\title{
Photovoltaic Ground Fault Detection Recommendations for Array Safety and Operation
}

\author{
Jack Flicker and Jay Johnson \\ Sandia National Laboratories, Albuquerque, NM 87123, United States
}

\begin{abstract}
PV faults have caused rooftop fires in the United States, Europe, and elsewhere in the world. One prominent cause of past electrical fires was the ground fault detection "blind spot" in fuse-based protection systems discovered by the Solar America Board for Codes and Standards (Solar ABCs) steering committee in 2011. Unfortunately, while a number of alternatives to ground fault fuses have been identified, there has been limited adoption or historical use of these technologies in the U.S. Analytical and numerical SPICE simulations were conducted for a wide variety of ground faults and array configurations to understand the limitations of fuse-based ground fault protection in PV systems and determine proper trip settings for alternative GFPDs. Simulation results were compared with experimental measurements on arrays to validate the SPICE model as well as provide direction on proper thresholding of residual current detector (RCD), current sense monitor (CSM) and isolation monitor $\left(R_{\text {iso }}\right)$ devices based on historical fault current data. We argue the combination of simulation results with historical data indicates robust settings are possible for each of these technologies to minimize unwanted tripping events while maximizing PV fault detection.
\end{abstract}

Index Terms - photovoltaics, ground fault, SPICE, balance of systems, RCD, isolation resistance measurement, differential current measurement, photovoltaic leakage current.

\section{INTRODUCTION}

A PV array ground fault is an electrical pathway between one or more array conductors and earth ground. Such faults are usually the result of mechanical [1], electrical, or chemical degradation of photovoltaic (PV) components, or mistakes made during installation. Fault types are defined by the location in the array and the impedance of the fault and can vary widely in the severity of their impact on array operations depending on these two factors. In order to protect the array during a ground fault event, a ground fault protection device (GFPD) is used to detect ground fault currents [2]. If the GFPD or another device also interrupts the fault current, the protection system is called a Ground Fault Detector/Interrupter (GFDI). The 2014 National Electrical Code (NEC) 690.5 specifies ground-fault protection requirements for grounded direct current (DC) photovoltaic arrays while NEC 690.35 defines the requirements for ungrounded systems [3]. Both of these sections require ground faults are detected and their presence is indicated.

Recently, a detection limitation, or "blind spot", in traditional fuse-based ground fault protection systems was identified for DC-grounded, AC-isolated PV systems that are most common in the United States [4]. The historical fire events presented in [4] have highlighted the incomplete protection provided by ground fault fuses in grounded arrays in the United States. Fortunately, in ungrounded, nonisolated, and hybrid systems, the ground fault blind spot does not exist [5].

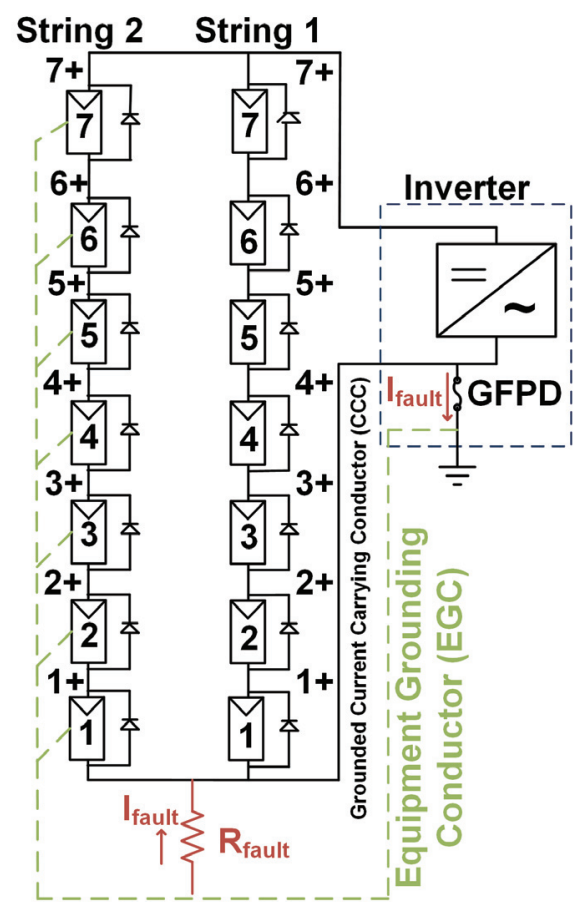

Fig. 1. Schematic for a DC-grounded PV array with two strings and a GFDI. The path of a ground fault on the negative current carrying conductor is denoted in red.

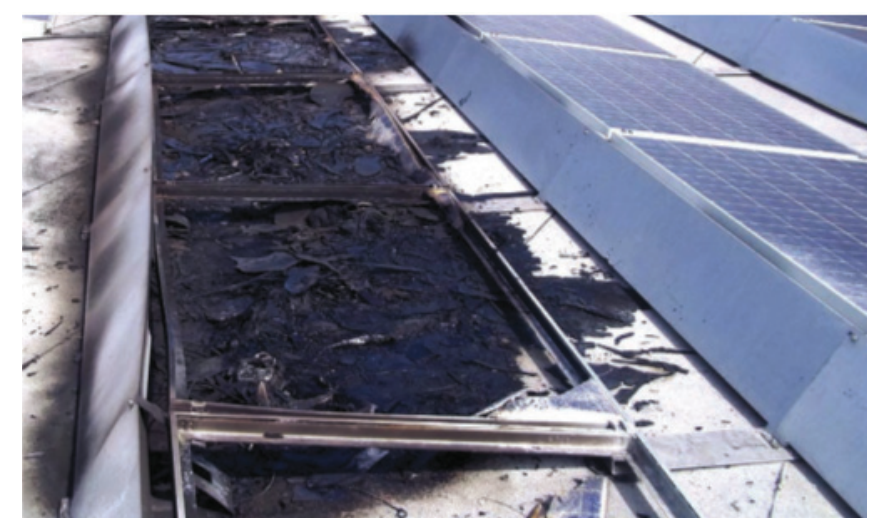

Fig. 2. A blind spot in a listed inverter's fuse-based groundfault protection scheme resulted in this fire damage. Historically, the ground-fault detection blind spot has caused multiple latent ground faults, in which a fault persisted for an extended period of time undetected, and ultimately resulted in a PV fire [6]. Latent ground faults can either be grounded 
conductor-to-ground faults (Fig. 1) or high-impedance ground faults on ungrounded conductors. The initial ground fault is generally not a fire hazard, but will remain latent because the fault current is too low to trip the inverter's GFPD fuse. At this point, the equipment grounding conductor (EGC) is energized and could represent a shock hazard resulting in injury, but does not possess enough current to cause a fire. However, if a second ground fault occurs in the array, fault current, which may be large, will bypass the interrupting device and the ground-fault protection system will not function as intended to prevent a fire. Fig. 2 shows the damage caused by the ground fault detection blind spot when two ground faults occur. Field experiments have further confirmed the existence of the ground fault detection blind spot [5].

This paper summarizes a three-year research program at Sandia National Laboratories to improve PV ground fault fire protection in the United States and presents suggested changes to national and international standards for four ground fault technologies. Specifically, we investigated the risk of ground faults in systems with different ground fault protection schemes and present recommendations for trip thresholds for fuse-based GFPD systems and three technologies that have not been regularly used in the United States, but were recommended by the Solar ABCs steering committee [5] for inclusion in future PV systems:

1. Replacing the rated fuse with a lower rating

2. Isolation monitoring $\left(\mathrm{R}_{\mathrm{iso}}\right)$

3. Residual current detection (RCD)

4. Current sense monitoring/relay (CSM/R)

Using numerical SPICE and analytical models as well as historical data from the field, each of these methods are discussed along with the basis for proper thresholding below. The thresholds were selected carefully to minimize the risk of unwanted tripping while maintaining the largest sensitivity for ground fault detection-i.e., protecting against the largest range of fault impedances and locations.

In Section II, a numerical SPICE simulation tool for faults on PV arrays is introduced and validated with real PV ground faults. This SPICE tool is used to calculate ground fault currents through GFPD fuses as well as demonstrate that reduction of GFPD size does not eliminate the ground fault detection blind spot. Section III presents historical data of RCD and CSM measurements for a variety of utility and residential scale systems. These results are used to determine appropriate trip thresholds. In Section IV, an analytical basis for $\mathrm{R}_{\text {iso }}$ measurements is presented. This basis is then used to define the appropriate $\mathrm{R}_{\text {iso }}$ trip threshold as a function of array size to balance safety with unwanted tripping events. In this work, a combination of historical data, analytical analysis, and simulations show that not all ground faults can be effectively detected, however, trip thresholds are developed that maximize the detection window for each detector type.

\section{FUSE-BASED GFPD}

The majority of the PV installations in the United States are DC-grounded systems with GFPD fuses. When a ground fault occurs in the system, the fault current travels through the fuse and trips it, if the current magnitude is large enough. In this section, we discuss the challenge of using this technology for certain ground faults and recommend new fuse ratings to improve the number of detectable ground faults.

From a GFPD fuse detection standpoint, the worst-case is when the fault location is on the grounded current carrying conductor (CCC), so this case is studied in detail below. In general, due to the non-linear nature of PV modules, the fault current for a fault located somewhere mid-string does not have a non-transcendental solution. However, when the fault exists at either of the CCCs, the fault acts as a current divider and an analytical solution is possible. In the following section, the fault current for a fault located at the grounded CCC (a blind spot fault scenario) is briefly presented (a full derivation is described at length in [7]). This analytical solution is corroborated by the validated SPICE simulations described earlier and used to determine the efficacy of replacing the listed fuse rating with a more sensitive type in order to close the ground fault blind spot.

\section{Analytical Model of System with Fuse-based GFPD}

To model current flow during a ground fault, the internal resistances of the conductors and the GFPD must be included because the current division between the fault path and the intended conduction path is heavily dependent on small internal resistances of the conductors.

Underwriters Laboratories Std. 1741 [8] mandates the maximum sizing of these protection devices based on the array size [9]. It is possible to install a lower rated fuse than mandated by UL 1741, though retrofitting fielded systems by replacing the fuse may invalidate the nationally recognized testing laboratory (NRTL) listing. In the ideal case, fuse ratings could be decreased freely without affecting the GFPD current; however, in reality, the fuse impedance depends on fuse ampere rating and thus affects the fault current. Fig. 3 shows a graph of fuse resistance vs. fuse rating for a number of 10x38 mm style fuses from multiple manufacturers.

The resistance of the fuse is inversely related to the fuse rating, so fuses with low trip ratings can have significant resistances. For example, the $0.1 \mathrm{~A}$ LittelFuse KLKD fuse has a resistance of $85.5 \Omega$ (Fig. 3). Such large resistances have significant effects on the GFPD current and fuse resistance must be balanced with fuse trip point in order to maximize GFPD fault detection capabilities. 


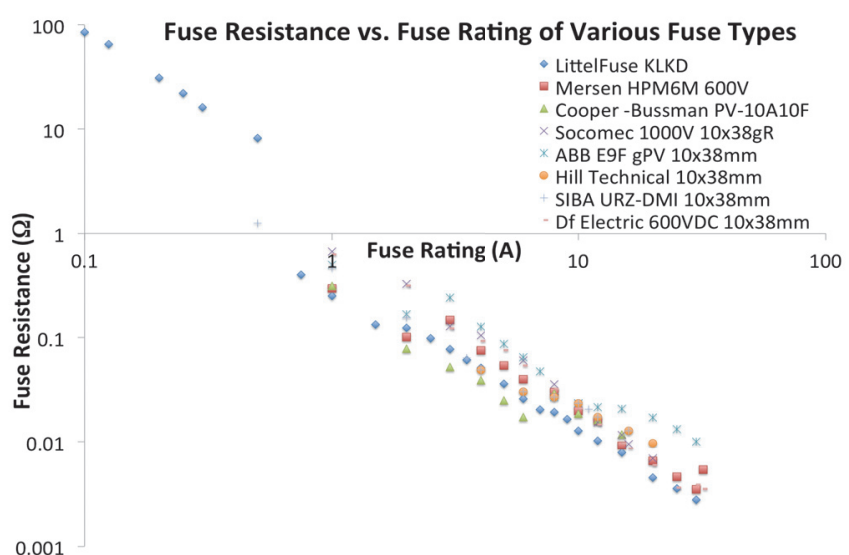

Fig. 3. GFPD resistance vs. rating for a variety of $10 \times 38 \mathrm{~mm}$ ("midget") fuses by various PV fuse manufacturers. In general, the more sensitive the fuse, the higher the intrinsic resistance [10-17].

This GFPD impedance means that the grounded CCC (the negative conductor in this scenario) is no longer at ground potential, but instead functionally grounded by the fuse. When a fuse with internal resistance is included in the model of a PV system, the conductor is at a voltage above ground potential, which introduces the possibility of ground faults from the grounded CCC through the EGC.

The circuit diagram in Fig. 4 shows the current paths for a single string providing a current (I) that has a fault in the grounded CCC at some point in the PV cabling (point A). The fault bisects the PV cable at some arbitrary point and acts as current divisor with part of the current $\left(\mathrm{I}_{\mathrm{GFPD}}\right)$ flowing through the GFPD and the remainder $\left(\mathrm{I}_{\mathrm{GFPD}}\right)$ flowing through the $\mathrm{CCC}$ as normal. $\mathrm{R}_{\mathrm{x}}$ denotes the resistance of the PV cabling included in the loop parallel to the GFPD current, while $\mathrm{R}_{\mathrm{y}}$ denotes the portion of PV cabling resistance that is not included in the fault loop. The sum of $R_{x}$ and $R_{y}$ is equal to $R_{P V}$ and the ratio of the two resistances is equal to the percentage of PV cabling that is faulted.

By Kirchoff's Current and Voltage Laws (KCL and KVL) and Ohm's Law, the voltage drop between $\mathrm{A}$ and $\mathrm{B}$ can be written as:

$\Delta V_{A, B}=I_{G F P D} \cdot\left(R_{G F P D}+R_{E G C}+R_{\text {fault }}\right)=\left(I-I_{G F P D}\right) \cdot\left(R_{\text {comb }}+R_{x}\right)$

By solving for $\mathrm{I}_{\mathrm{GFPD}}$, (1) can be written as:

$$
I_{G F P D}=\frac{I \cdot\left(R_{c o m b}+R_{x}\right)}{R_{G F P D}+R_{E G C}+R_{c o m b}+R_{x}}
$$

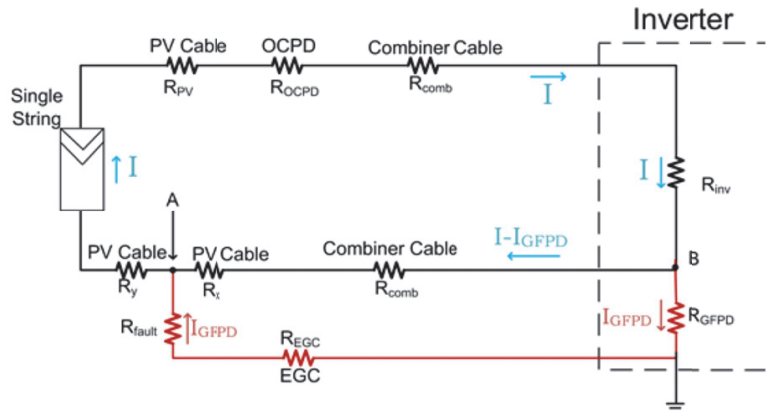

Fig. 4. Circuit diagram of grounded CCC fault of an array with leakage current and combiner and recombiner boxes. Resistances and currents used in $\mathrm{KVL} / \mathrm{KCL}$ equations are shown.

The ground fault on the grounded CCC is a minor perturbation from normal operating conditions of the array. Therefore, the operating points of the modules on the I-V curve are nearly unaltered during a negative CCC ground fault and the module current output, $\mathrm{I}$, can be described by $\mathrm{I}_{\mathrm{mp}}$ when the modules have enough irradiance to source their maximum power (worst-case scenario). Therefore, (2) reduces to:

$$
I_{G F P D}=\frac{I_{m p} \cdot\left(R_{c o m b}+R_{x}\right)}{\left(R_{G F P D}+R_{E G C}+R_{\text {fault }}+R_{c o m b}+R_{x}\right)}
$$

This same procedure can be repeated for a larger PV array, presented in Fig. 5. For an array with recombiner boxes, each having $\mathrm{D}$ parallel combiner boxes composed of $\mathrm{C}$ parallel strings per combiner box and supplying current (I) to a load, it is assumed that (C-1) parallel strings are unfaulted with a source current equal to $\mathrm{I}_{2}$ and that all strings have a leakage to the EGC equal to $I_{\text {leak }}[7]$.

The KVL analysis of the circuit between points A and B can be described by:

$$
\begin{aligned}
& \left(I+I_{\text {leak }}-I_{\text {faut }}\right) \cdot R_{\text {reconb }}+\left(I+I_{\text {leak }}-I_{\text {fuut }}-(D-1) C I_{2}\right) \cdot R_{\text {conb }}+\left(I+I_{\text {leak }}-I_{\text {faut }}-(D-1) \cdot C \cdot I_{2}-(C-1) \cdot I_{2}\right) \cdot R_{x} \\
& =\left(I_{\text {fault }}-I_{\text {leak }}\right) \cdot R_{\text {GFPD }}+\left(I_{\text {fault }}-I_{\text {leal }}\right) \cdot R_{\text {ECC }}+I_{\text {fuath }} \cdot R_{\text {fault }}
\end{aligned}
$$

As before, the module output is equivalent to the maximum power current so the currents can be described by:

$$
\begin{aligned}
& I=D \cdot C \cdot I_{m p} \\
& I_{2}=I_{m p}
\end{aligned}
$$




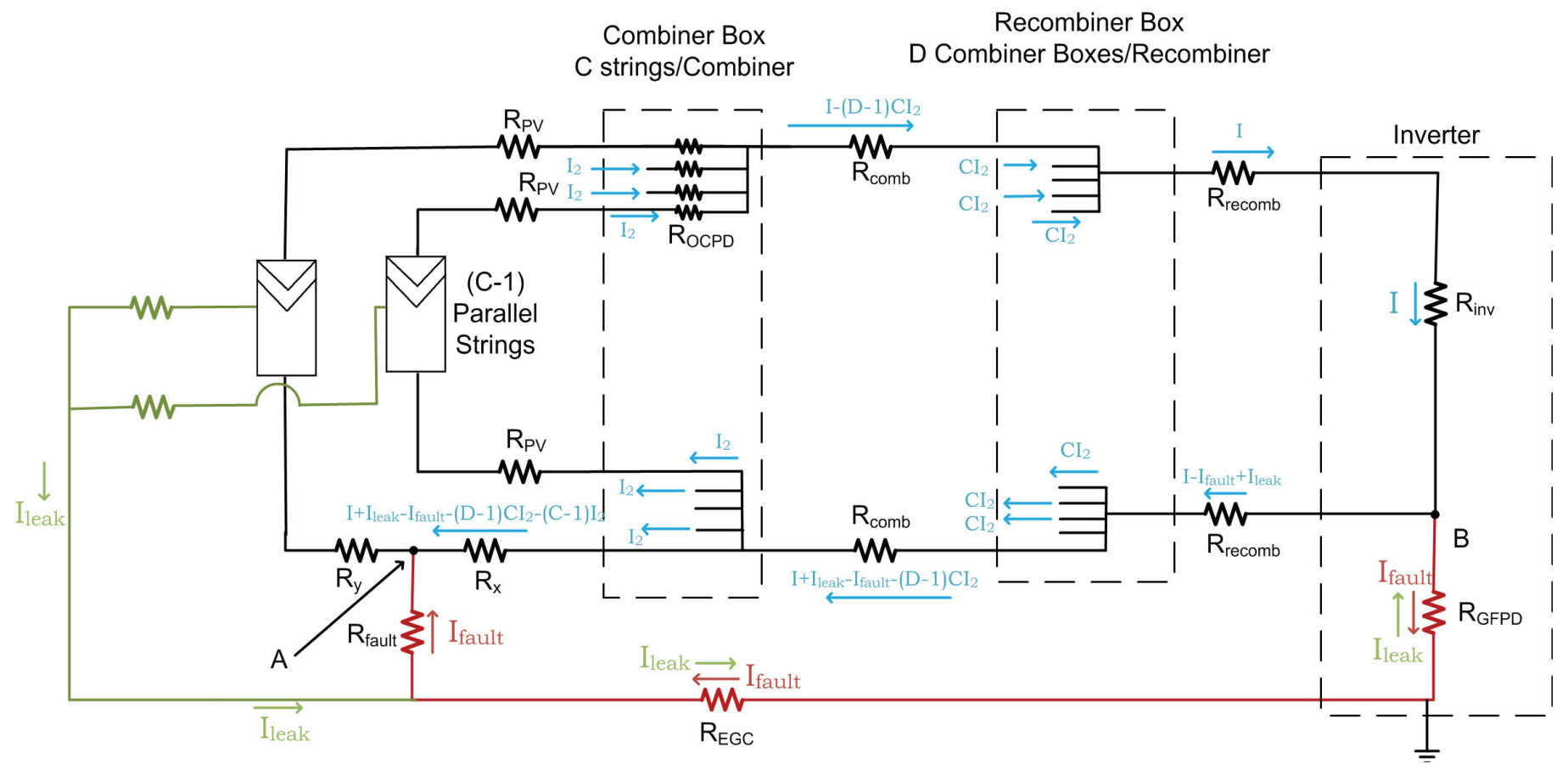

Fig. 5. Circuit diagram of negative CCC fault with a single string at an arbitrary point in the negative PV cabling. The ratio of $R_{x}$ and $R_{y}$ indicates the percentage of PV cabling faulted. Resistances and currents used in Kirchoff's Voltage Law equations are shown.

So, by inserting (5) into (4) and solving for $\mathrm{I}_{\text {fault }}$, the fault current can be described by:

$I_{\text {fault }}=\frac{I_{m p} \cdot\left(D \cdot C \cdot R_{\text {recomb }}+C \cdot R_{\text {comb }}+R_{x}\right)+I_{\text {leak }} \cdot\left(R_{\text {recomb }}+R_{\text {comb }}+R_{x}+R_{\text {GFPD }}+R_{E G C}\right)}{\left(R_{G F P D}+R_{E G C}+R_{\text {fault }}+R_{\text {recomb }}+R_{\text {comb }}+R_{x}\right)}$

The GFPD current is the difference in the fault and leakage currents (since they are opposite in direction), so $\mathrm{I}_{\text {fault }}$ can be transformed into $\mathrm{I}_{\mathrm{GFPD}}$ by:

$$
I_{\text {GFPD }}=I_{\text {leak }}-I_{\text {fault }}
$$

Finally, (6) can be solved in terms of $\mathrm{I}_{\mathrm{GFPD}}$ by substituting (7):

$I_{\text {faut }}=I_{\text {leak }}-\frac{I_{m p} \cdot\left(D \cdot C \cdot R_{\text {recomb }}+C \cdot R_{\text {conb }}+R_{x}\right)+I_{\text {leak }} \cdot\left(R_{\text {recomb }}+R_{\text {comb }}+R_{x}+R_{\text {GFPD }}+R_{E G C}\right)}{\left(R_{G F P D}+R_{E G C}+R_{\text {fautt }}+R_{\text {recomb }}+R_{\text {comb }}+R_{x}\right)}$

In simulations, the recombiner topology has not been used $\left(\mathrm{D}=1, \mathrm{R}_{\mathrm{recomb}}=0 \Omega\right.$, so the equation for $\mathrm{I}_{\mathrm{GFPD}}$ shown as (8) becomes:

$I_{G F P D}=I_{\text {leak }}-\frac{I_{\text {mp }} \cdot\left(C \cdot R_{\text {comb }}+R_{x}\right)+I_{\text {leak }} \cdot\left(R_{\text {comb }}+R_{x}+R_{\text {GFPD }}+R_{E G C}\right)}{\left(R_{G F P D}+R_{E G C}+R_{\text {fault }}+R_{\text {comb }}+R_{x}\right)}$

\section{Numerical Model of System with Fuse-based GFPD}

The use of computer circuit simulation tools can describe the behavior of a PV system for a wide variety of fault conditions [10]. Since PV modules are non-linear circuits, their behavior is difficult to describe analytically without transcendental equations. One common method of modeling PV systems is through circuit simulation using Simulation
Program with Integrated Circuit Emphasis (SPICE). SPICE [11] is a general-purpose, open source, analog circuit simulator used to predict circuit behavior. In order to understand the behavior of an array under a wide variety of different electrical fault conditions as well as analyze the detection thresholds of different GFPD technologies, a PV array circuit simulation tool was created with multiple modules connected to a central inverter. Details of the model and a description of the array under various faulted and unfaulted conditions are described at length in [12].

PV modules are non-linear circuits. Their behavior is difficult to describe analytically without transcendental equations, but the use of computer circuit simulations can describe the behavior of a PV system for a wide variety of fault conditions [13]. A common method of circuit simulation is the use of the Simulation Program with Integrated Circuit Emphasis (SPICE). SPICE, originally developed at the University of California, Berkeley Electronics Research Laboratory in 1973 [14], is a general-purpose, open source, analog circuit simulator used to predict circuit behavior. In this work, the program MacSPICE, a derivative of SPICE3f4, was used to analyze the behavior of PV systems in various array configurations and ground-fault conditions [15].

The SPICE model of the PV array is accomplished through the construction of a PV module using a one-diode model, as depicted in Fig. 6. These modules consist of an ideal current source $\left(I_{s c}\right)$ in parallel with a diode and shunt resistance $\left(R_{\text {sh }}\right)$ in series with a series resistance $\left(\mathrm{R}_{\mathrm{s}}\right)$. In order to increase the $\mathrm{V}_{\mathrm{oc}}$ of the module above the voltage drop of a regular diode $(\sim 0.6 \mathrm{~V})$, the ideality constant of the diode is increased [16]. 


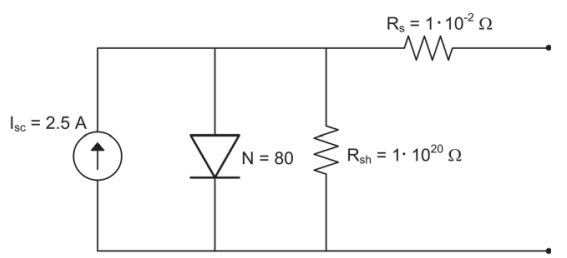

Fig. 6. One diode model for single PV module

This one diode model allows for total customization of the module IV curve. The slope of the IV curve around $\mathrm{V}_{\mathrm{oc}}$ is controlled by the value of $R_{\mathrm{sh}}$. The slope of the IV curve around $I_{s c}$ is controlled by the value of $R_{s}$. The value of the current source determines the value of $\mathrm{I}_{\mathrm{sc}}$, while the diode ideality constant, $\mathrm{N}$, determines the $\mathrm{V}_{\mathrm{oc}}$, shown in Fig. 7.

For the purposes of this work, the one-diode model is constructed to approximate a nearly perfect photovoltaic module. The current source is set to supply $2.5 \mathrm{~A}$ at short circuit, the diode has an ideality factor of $\mathrm{N}=80$, the shunt resistance is set $1 \cdot 10^{20} \Omega$ and the series resistance is set to 10 $\mathrm{m} \Omega$. This module gives an IV curve (green trace in Fig. 7) with $\mathrm{I}_{\mathrm{sc}}$ of $2.5 \mathrm{~A}, \mathrm{~V}_{\mathrm{oc}}$ of $56 \mathrm{~V}$, and $\mathrm{P}_{\mathrm{mp}}$ of $118 \mathrm{~W}$. The max power point has a current of $\mathrm{I}_{\mathrm{mp}}=2.4 \mathrm{~A}$ and a voltage of $\mathrm{V}_{\mathrm{mp}}=49.2 \mathrm{~V}$.

To determine the behavior of PV arrays during a ground fault, a model was created composed of a number of strings wired in parallel. Each string is composed of seven modules in series (Fig. 1). Each module is connected to a bypass diode $\left(\mathrm{I}_{\mathrm{sat}}=4.7 \cdot 10^{-12} \mathrm{~A}, \mathrm{~N}=1\right)$. The array is wired to a resistor, as a basic approximation of the real input impedance of an inverter. The resistance connected to the array in all the simulations is set at the resistance required to generate maximum $P V$ power, $R_{m p}$, of the unfaulted array.

A DC-grounded, AC-isolated central inverter is modeled in each of the simulations because this topology is susceptible to faults that are undetected by the ground fault fuse. Only the real component of the inverter impedance is modeled, although physical inverters are a complex system containing transistors, capacitors, and switching controls [17]. However, if the voltage ripple and max power tracking [18] are ignored, the PV system can be approximated by a steady state DC system with a constant resistance. This means that the imaginary components of the inverter impedance have no effect on the steady state solution before and after the fault occurrence. Transient effects of the system and their correspondence to steady-state solutions is studied in more detail in [19].

Based on these factors, it is unlikely that the imaginary components of the inverter impedance will affect GFPD response and the inverter may be simplified to a resistive element. However, more advanced modeling of the inverter/PV system interaction does warrant future study.

With this model of a PV system, various ground faults were modeled. The ground faults can occur inside modules, in conductors between modules, and in DC runs; however, due to the limitations of the SPICE model, faults within the module to the frame are not considered. In the SPICE array models, a fault to ground is composed of a controllable switch and a resistor. As a method of categorizing the location of the fault on the faulted string, the fault is named for the module and terminal that the fault originates. For example, the fault shown in Fig. 1 would be labeled as 1-, since the fault occurs from ground to the negative terminal of module \#1. It is to be noted that a ground faults on subsequent module terminals are equivalent. For example, a fault at $4+$ is synonymous with a fault at 5-. For consistency, the nomenclature will only refer to ground faults at the positive terminal of a module.

The shunt resistance $\left(\mathrm{R}_{\text {shunt }}\right)$ around the ground fault switch is implicit in SPICE simulations and is present for any device that results in a sudden, discrete voltage change (e.g. switches, diodes). This is necessary in nodal analysis programs, such as SPICE, to prevent floating voltages that can lead to singular conduction matrices and unstable circuit simulations. This resistance is set to the reciprocal of the minimum conductance $\left(\mathrm{G}_{\min }\right)$. For this series of simulations, $\mathrm{G}_{\min }$ is set to $1 \cdot 10^{-10}$ resulting in a value for $I_{\text {shunt }}$ in the range of nanoamperes. Due to this modeling limitation, no element ever has zero current flow, but will instead have some very small nonzero current dependent on the value of $\mathrm{G}_{\min }$.

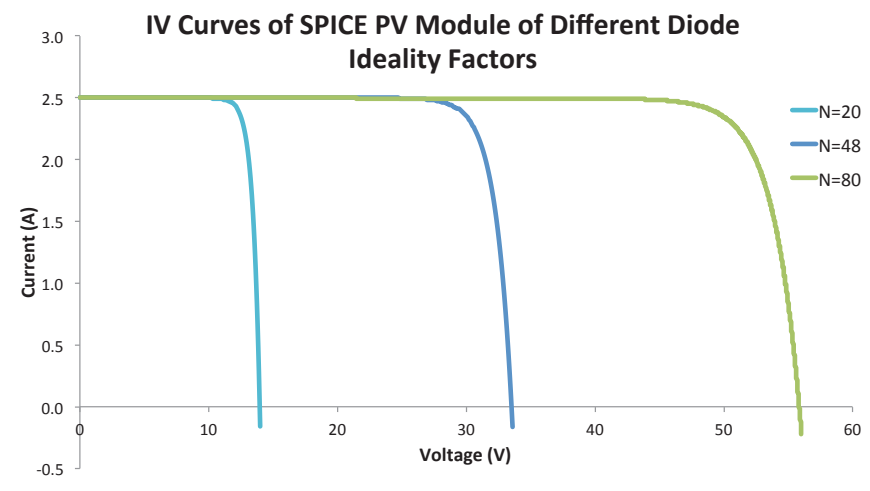

Fig. 7. IV curves for one-diode PV module as diode ideality factor, $\mathrm{N}$, is varied.

In order to validate the SPICE model, a number of the simulated fault types [20] were compared to field experimental studies performed at the Distributed Energy Technologies Laboratory (DETL) at Sandia National Laboratories using a set of power resistors as a fault pathway in an array connected to either an inverter or a variable load bank surrogate set to the maximum power point (MPP) of the unfaulted array [21]. 


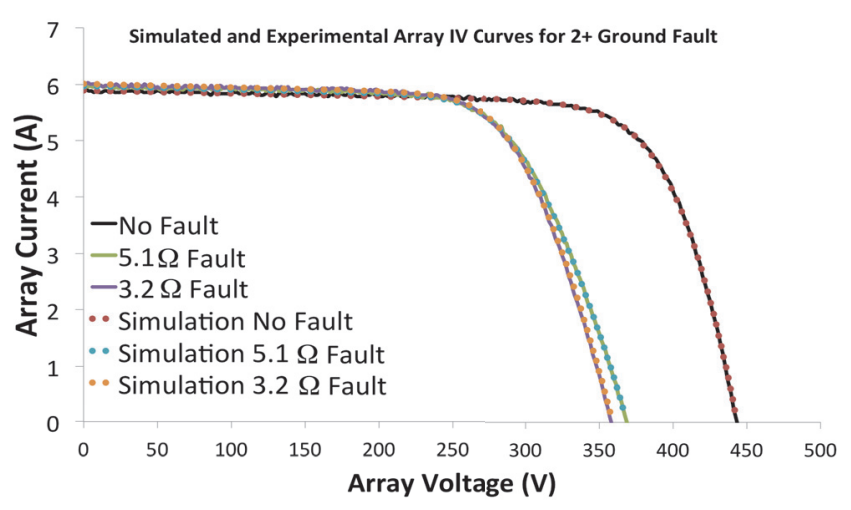

Fig. 8. Experimental IV curves of faulted and unfaulted states (solid lines) overlaid with SPICE simulations (dots) for different resistance ground faults.

The SPICE PV model was calibrated using IV curves of the unfaulted array taken using a Daystar DS-100C IV curve tracer. The physical PV array at DETL was composed of two strings of seven $200 \mathrm{~W}$ monocrystalline Si modules. After input of the unfaulted single diode module parameters $\left(\mathrm{I}_{\mathrm{sc}}, \mathrm{R}_{\mathrm{s}}\right.$, $\mathrm{R}_{\mathrm{sh}}, \mathrm{N}$, and $\left.\mathrm{I}_{\text {leak }}\right)$ [16] to correctly replicate the IV curve, fault experiments were conducted in simulation and on the actual PV array at DETL to validate the ground fault model. Faults were installed between modules using MC4 T-branch connectors to the metal array racking. The fault current and voltage and array current and voltage were collected with a Tektronix DPO3014 oscilloscope, two Tektronix P5200 differential voltage probes, and two Tektronix TCP303 current probes. The SPICE model closely predicted the IV curve for both 5.1 and $3.2 \Omega$ ground faults, shown in Fig. 8, listed as $2+$ to ground $\left(\mathrm{N}+\right.$ indicates the positive terminal of the $\mathrm{N}^{\text {th }}$ module from the grounded conductor).

To validate the SPICE model without inverter dynamics, the DETL PV array was connected to a load bank with impedance $(55.6 \Omega)$ approximately equal to the inverter impedance at the MPP. Resistive faults of $3.2,5.1,10.5$, and $22.4 \Omega$ were established for a variety of different fault types. Only ground faults are in the scope of this work, although the full collection of ground, intra-string, inter-string, series, and arc faults were included in [21].

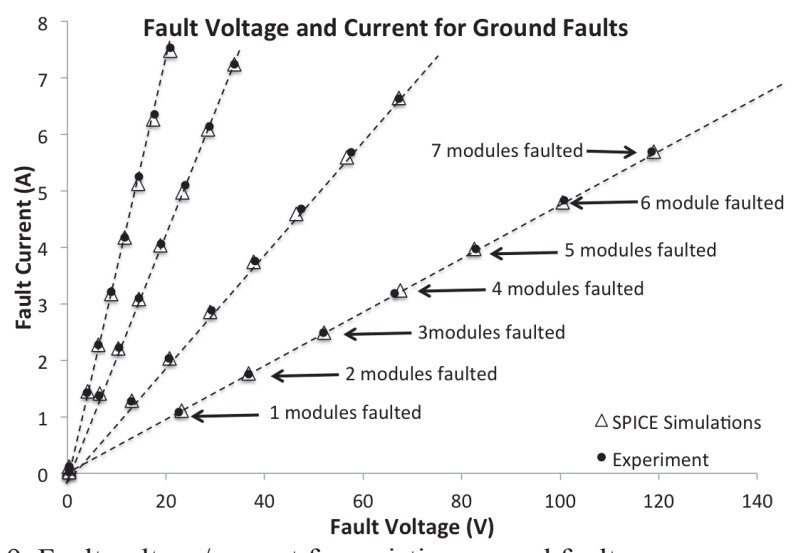

Fig. 9. Fault voltage/current for resistive ground faults.
Fig. 9 shows the results of experimental ground fault tests of the PV array using power resistors as the array load as well as the ground fault pathway. The dashed lines indicate the different resistances $(3.2,5.1,10.5$, and $22.4 \Omega)$ used for the faults. The figure shows excellent correlation between the simulated fault current/voltage and that measured experimentally.

The SPICE simulations matched the experimental data points well $(<5 \%$ error) for all fault conditions studied. Similar matching results were obtained for fault types other than ground faults as well. However, as more modules were faulted, the SPICE simulations slightly under predict both the fault current and fault voltage. This error is likely due to differences in the fault resistance between the values used in simulation and the actual resistors, a slight mismatch in the series resistance of the module model, or parasitic resistances due to PV wiring and interconnects.

A SPICE model was created with the internal resistance of the conductors and GFPD in order to investigate ground faults involving the negative CCC. Arrays were simulated with a fault located midway on the DC home-run cable $\left(\mathrm{R}_{\mathrm{x}}=\mathrm{R}_{\mathrm{y}}\right)$. Resistive parasitics for wiring and other protection devices were inserted into the model as determined from a mixture of datasheets, theoretical calculations, and field measurements, as detailed more extensively in [5]. The value of the inverter resistor was set to the MPP of the unfaulted array. The negative inverter connection was connected to ground through the fuse.

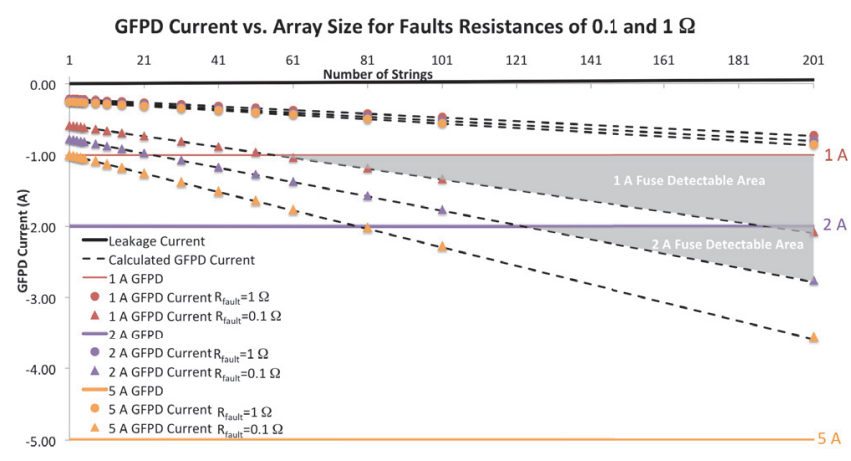

Fig. 10. Graph of GFPD current vs. array size for various GFPD and fault resistances. The color of the line indicates GFPD resistance. Red traces denote 1 A $(0.252 \Omega)$, while purple and orange traces denote $2 \mathrm{~A}(0.124 \Omega)$, and $5 \mathrm{~A}(0.0363 \Omega)$, respectively. Only the $1 \mathrm{~A}$ and $2 \mathrm{~A}$ fuses are sensitive enough to trip due to the blind spot fault. The region where $\mathrm{I}_{\mathrm{GFPD}}$ is larger than the trip point is colored in gray.

\section{Results of Analytical and Numerical Modeling}

To investigate the effect of fuse resistance on fault current, simulations were carried out for fuse resistances of 85.5, 22, $8.16, \quad 0.252, \quad 0.124$, and $0.0363 \Omega$ (LittelFuse KLKD resistances for $0.1,0.25,0.5,1,2$, and 5 A fuses [22], respectively) with fault resistances of $0.1,1$, and $25 \Omega$. Fig. 10 shows the results of the simulations for 1,2, and 5 A GFPD 
fuses and fault resistances of 0.1 and $1 \Omega$. Simulations with a $1 \mathrm{~A}(0.252 \Omega), 2 \mathrm{~A}(0.125 \Omega)$, and $5 \mathrm{~A}(0.0363 \Omega)$ are shown as red, purple, and orange points, respectively. Triangles indicate a fault resistance of $0.1 \Omega$ while circles represent a 1 $\Omega$ resistance. Solid lines at 1,2 , and 5 A denote the fuse ratings with color corresponding to the fuse trip point. The GFPD current calculated by (8) is denoted by a dashed line for each set of fuse and fault resistances.

The GFPD current is linear with number of strings for all fuse ratings and fault resistances. For all arrays up to 201 strings, only the $1 \mathrm{~A}$ and 2 A GFPDs (at fault resistance of 0.1 $\Omega$ ) allow enough GFPD current to trip the fuse (shaded regions denote where $I_{\text {GFPD }}>I_{\text {trip }}$ ) The 1 A GFPD only detects the ground fault in arrays larger than 56 strings while the $2 \mathrm{~A}$ GFPD detects faults in arrays larger than 124 strings. The orange traces do not reach $5 \mathrm{~A}$ even for 201 strings, so a $5 \mathrm{~A}$ GFPD would never trip for a blind spot ground fault.

It is tempting to believe that decreasing the fuse rating will increase the number of detectable blind spot faults. However, the decrease in trip point is more than offset by the increased GFPD resistance, so fuses with low ratings will detect fewer faults to the grounded CCC. Fig. 11 shows the simulations results for 0.1 (green), 0.25 (purple), and 0.5 A (blue) GFPD fuse ratings at $\mathrm{R}_{\text {fault }}$ of 0.1 and $1 \Omega$. In each case, due to the increase in fuse resistance, the GFPD current is far too small to trip the fuses.

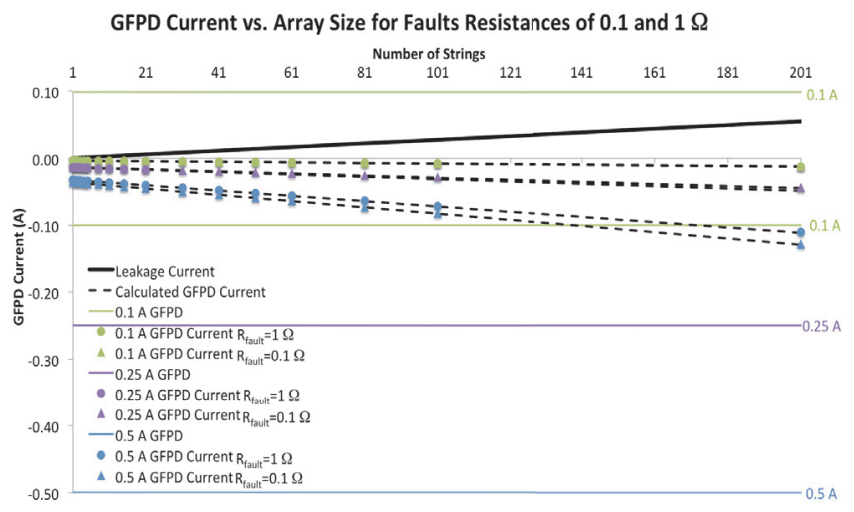

Fig. 11. Graph of GFPD current vs. array size for various GFPD and fault resistances. The color of the line indicates GFPD resistance. Green traces denote 0.1 A $(85.5 \Omega)$, while purple and blue traces denote $0.25 \mathrm{~A}(22 \Omega)$, and $0.5 \mathrm{~A}(8.16 \Omega)$, respectively. Even though the fuses have low trip points, due to the increased fuse resistance, the GFPD current is below the fuse trip point and the blind spot window is increased.

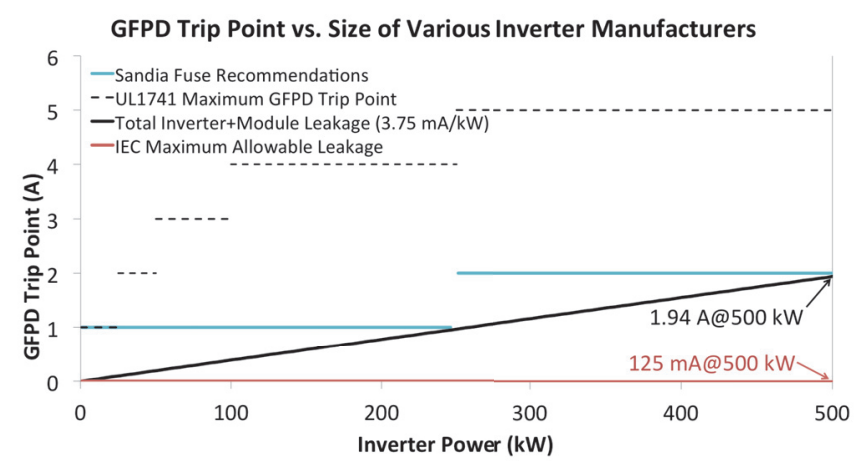

Fig. 12. Graph of GFPD current vs. array size for various GFPD and fault resistances. The color of the line indicates GFPD resistance.

\section{Discussion}

Of the fuse sizes studied $(0.1,0.25,0.5,1,2$, and $5 \mathrm{~A})$, only the $1 \mathrm{~A}$ and $2 \mathrm{~A}$ fuses (at $\mathrm{R}_{\text {fault }}=0.1 \Omega$ ) have the combination of low trip point and low resistance needed to detect the blind spot fault for large array sizes (above 56 and 124 strings, respectively). While, logically, it may be tempting to reduce undetected faults by decreasing fuse rating, this actually increases the detection blind spot due to increased fuse resistance. To truly limit the size of the blind spot, fuse rating and fuse resistance must both be considered and optimized and simply replacing one fuse with a lower rated one may actually increase the detection blind spot. Therefore, decreasing the fuse size is not an appropriate solution to the ground fault blind spot and other GFPD devices are necessary.

Yet, based on the modeling results, some improvements can be made to the UL standard. Reducing UL 1741 GFPD fuse ratings to $1 \mathrm{~A}$ for all $600 \mathrm{~V}$ installations below $250 \mathrm{~kW}$ will increase the detection window for blind spot ground faults. Higher voltage and power installations may require a 2 A fuse to prevent unwanted tripping in PV systems with large leakage currents. The UL 1741 trip points for $600 \mathrm{~V}$ PV systems are shown in Fig. 12 along with new recommendations for lower limits. Fig. 12 also shows the maximum IEC 61215 module leakage limits $\left(40 \mathrm{M} \Omega \cdot \mathrm{m}^{2}\right)$ for a $1000 \mathrm{~V}$ array with $10 \%$ efficient modules (red trace); although these are well below the suggested trip limits. Experimental measurements by Sandia have confirmed that PV inverters contribute a significant amount of current to overall system leakage [23, 24]. A higher overhead than the module leakage is necessary additionally since there may be additional transients from lightning or inverter noise through the ground bond [5].

The new fuse sizing recommendations listed here take into account a large overhead for these added noise sources. The total leakage for modules and inverter componentry is included in Fig. 10 (black trace) assuming the inverter adds cycle averaged noise of $3.63 \mathrm{~mA} / \mathrm{kW}$, which is the largest value measured by Sandia on operational inverters and is typically significantly lower (see Fig. 14 and the next section for a more detailed discussion). The overhead included allows for a large amount of leakage on the GFPD injected by the inverter (16 times that injected by the modules). 
As decreasing the fuse size is not an appropriate solution to the ground fault blind spot, other GFPD devices are necessary. The remainder of this paper offers suggestions for two alternative ground fault detection techniques with trip points validated with experimental results.

\section{Residual Current Detection/ Current Sense MONITORING}

RCDs and CSMs are combined in this section because both operate on the principle of detection of stray current flows in the presence of a fault condition, and the current magnitude will be the same for either technology. CSMs operate by monitoring (via a current transformer) the current flow through the ground bond. Excessive current flow through the ground bond (greater than array and BOS component leakage) is assumed to be caused by a ground fault and, if the measured current is above a pre-set threshold, the CSM trips. RCDs operate by monitoring the differential current flow in the positive and negative CCCs-often inside the inverter. Current imbalance between the two CCCs above a preset threshold is assumed to be caused by a ground fault and trips the RCD. In non-AC-isolated systems with transformerless inverters, the fault current is fed from the $\mathrm{AC}$ side of the system as well, so the RCD can be installed on the AC side of the inverter. Fig. 14 shows a circuit schematic detailing the different installation positions of RCD and CSM devices.

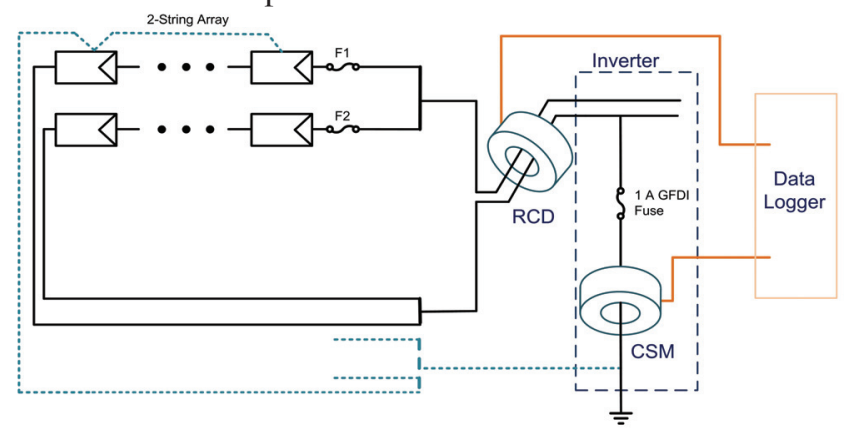

Fig. 14. RCD vs. CSM measurements on a PV array.

For both RCD and CSM, the trip threshold is freely selectable and, in either configuration, does not modify the conductive pathway being monitored. Rather, both solutions inductively measure current in the monitored pathway. This approach maintains the inverter certification listing even after retrofit by ensuring that the manufacturer's factory installed ground fault protection system functions exactly as originally evaluated by a NRTL.

The types of detectable ground faults for these solutions depend on the threshold used to define the presence of a fault. If this trip threshold is too low, there will be nuisance trip events resulting from module and BOS component leakage currents; but if the threshold is too high, higher impedance ground faults will go undetected. Both RCD and CSM methods could register array leakage as a type of fault, therefore, the generalized detection threshold must be set above the maximum leakage current in all unfaulted operating conditions (meteorological, topological, and electrical).

\section{Test Case \#1}

To understand the influence of the meteorological conditions on RCD measurements, Sandia National Labs worked with a large, utility-scale PV operator to collect the system leakage values from $340500 \mathrm{~kW}$ co-located inverters in a desert environment [24].

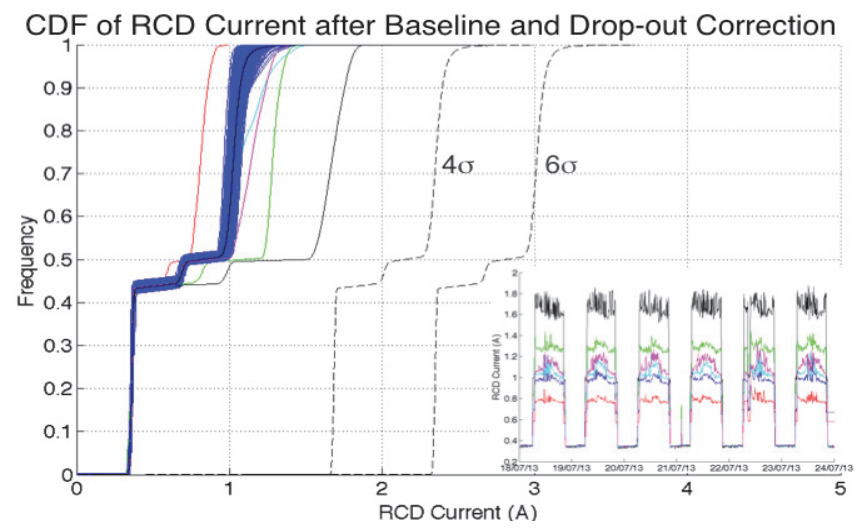

Fig. 13. CDFs corrected for baseline and data dropouts. Most of the CDFs are clustered together with a few outlier inverters with higher or lower leakages (shown in inset). Assuming a normal distribution, the $+4 \sigma$ and $+6 \sigma$ limits of the average CDF are shown as black dashed lines.

\section{Test Case \#1 Experimental}

The RCD system leakages for each inverter were measured at one-minute intervals for over a year (1 January 2013 to 3 August 2014). In compliance with UL 1741, each inverter has a GFPD fuse rated at 5 A to protect against ground faults. This conservative threshold was chosen to maximize the detection of ground faults while eliminating unwanted tripping events due to electromagnetic interference (EMI), module/inverter leakage, and meteorological events (i.e. lightning).

\section{Test Case \#1 Results}

Fig. 13 shows the cumulative distribution functions (CDFs), corrected for baseline deviations and data dropouts of all 340 RCDs for the time period of data collection [24]. For a given CDF curve, a shift to the right indicates higher leakages in the inverter, possibly due to an incorrect baseline value or a high impedance ground fault. If the effect of data reliability is corrected (which could be done via simple, on-board programming), such as baselining the inverter leakage each night when the inverter is disconnected and eliminating repeated data due to dropouts, the CDFs of all 340 inverters are tightly distributed. All but five of the 340 inverters (colored in blue in Fig. 13) lie within a range of 1.14-1.51 A $99.99 \%$ of the time. The five inverters that act as outliers (CDFs are colors other than blue) demonstrate either higher or lower leakage values than the average (blue). The RCD 
values over a six-day period of these outlier inverters along with a "typical inverter" (blue) are shown in the inset. The inverters corresponding to the magenta, green, and black curves show higher measured leakage values during the day while the red curve corresponds to a lower measured leakage value. It should be noted that, although the baseline (nighttime) value for each inverter is the same, the turnoff/turn-on values scale with the daytime leakage of the inverter, indicating that the increased or decreased RCD current may be due to a proportionality (gain) problem in the RCD rather than an actual increase of leakage in the inverter.

The $4 \sigma$ and $6 \sigma$ confidence bands of the average CDF of all the inverters (both "normal" and the five outlier inverters) is shown as dashed black lines in Fig. 13. Note that these curves represent RCD values that are exceedingly rare given the data population: $\operatorname{Pr}(\mathrm{x} \geq \mu+4 \sigma)=0.00317 \%$ and $\operatorname{Pr}(\mathrm{x} \geq \mu+6 \sigma)=$ $9.87 \cdot 10^{-8} \%$. These statistical metrics can be used to establish thresholding rules based on the requirements of the inverter manufacturer, O\&M company, plant owner, or standardsmaking panel. For example, there is a $4 \sigma$ confidence that $99.999 \%$ of measured leakage values are below $3.1994 \mathrm{~A}$ and a $6 \sigma$ confidence that $99.999 \%$ of the RCD values are below 3.8616 A (Table I). A set point of 5 A (as currently mandated by UL 1741) corresponds to an eight-nines confidence of the $4 \sigma$ confidence band.

\section{Test Case \#1 Discussion}

For the inverter model at this location, the RCD thresholds could be reduced to improve high impedance ground fault sensitivity without additional unwanted tripping events. For the inverters in this installation, the RCD trip point could be lowered from $5 \mathrm{~A}$ to as low as $2.5 \mathrm{~A}$ with six 9's confidence that any unfaulted RCD current measurement would be lower than the ground fault setpoint. Statistically, this would correspond to 0.5 trips/inverter/year if single, raw 1-minute $\mathrm{RCD}$ data were considered. In practice, this number could be reduced even further through more advanced data analysis techniques, such as data windowing, averaging, data error correction, or step change analysis.

Table I: High frequency values of the CDFs for the average of all inverters as well as the $4 \sigma$ and $6 \sigma$ confidence bands.

\begin{tabular}{|l|lll|}
\hline Frequency & Average & $4 \sigma$ & $6 \sigma$ \\
\hline 99 & 1.1825 & 2.5067 & 3.1688 \\
99.9 & 1.6437 & 2.9679 & 3.6300 \\
99.99 & 1.8028 & 3.1270 & 3.7892 \\
99.999 & 1.8752 & 3.1994 & 3.8616 \\
99.9999 & 2.4891 & 3.8133 & 4.4754 \\
99.99999 & 2.8759 & 4.2001 & 4.8623 \\
99.999999 & 3.6827 & 5.0069 & 5.6690 \\
\hline
\end{tabular}

\section{Test Case \#2}

In addition to working with array operators, since 2013, Sandia National Laboratories has worked with a major engineering, procurement and construction (EPC) firm to extensively install alternatives to fuse-based GFPDs throughout its fleet of PV systems on commercial rooftop systems [25]. A balance of accuracy, cost, and serviceability led the EPC to decide to install string-level inverters equipped with isolation monitor and RCD technologies on new systems and to retrofit central inverters with CSM devices. Currently, the EPC has retrofitted 331 central inverters, representing 109 MW of inverter capacity, with the CSM technology at an aggressive ground fault trip setting of $100 \mathrm{~mA}$.

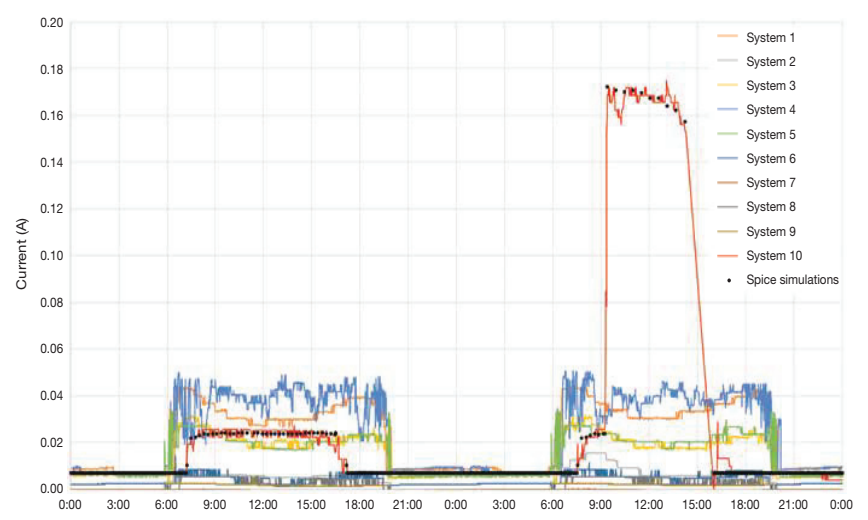

Fig. 15. CSM data for 10 different PV systems, one of which (in red) developed a ground fault with a magnitude of approximately 170 $\mathrm{mA}$. The black dots show the results from Sandia's SPICE model for the ground fault.

\section{Test Case \#2 Results}

Fig. 15 reports two days of measured CSM current values for nine healthy PV systems and one system that developed a ground fault. These data were collected from systems deployed using three different inverters - all of which were in the $250 \mathrm{~kW}$ to $500 \mathrm{~kW}$ capacity range - and three different module types. The measured current values for the healthy systems range from $5 \mathrm{~mA}$, the lower limit for the installed CSM kit, to about $50 \mathrm{~mA}$. Although these measured values include current contributed by the entire DC system, the magnitude of healthy daytime CSM values is largely dependent on the ground current from the inverter.

As illustrated by the black dots in Fig. 15, Sandia's SPICE simulation tool can be used to model the fault current for this system and determine proper alarm thresholds for arrays as well as understand array behavior based on a wide variety of fault locations and impedances.

Table II summarizes the experience of the EPC firm before and after it implemented CSM equipment on commercial rooftops. Prior to deploying CSM solutions, the EPC experienced nine thermal events in systems protected by traditional fuse-based GFPDs. These fires occurred over a 6year period and resulted in a range of damage. In the 3 years 
since the wide-scale rollout of advanced ground fault solutions, the EPC has not experienced a single fire incident in systems protected by one of these solutions. In that same period of time, central inverters equipped with CSM equipment have detected a total of 20 ground faults across the EPC fleet that its service personnel were able to identify and repair. Many of these incidents were dangerous, high impedance faults to conductors with low potential to ground that would have persisted indefinitely were fuse-based GFPDs the only fault detection method utilized.

RCD and CSM measurements, especially in the sub-second time period, show that inverter-to-ground leakage component account for a large portion of the overall system leakage when the PV system is exporting power [23]. The exact magnitude and waveform of this inverter-to-ground leakage can vary widely from manufacturer to manufacturer; CSM leakage data collected at $10 \mathrm{kHz}$ for 0.1 seconds with Tektronix TCP303 current probes is shown in Fig. 16 for six residential PV inverters. The CSM measurements are subject to significant inverter switching noise, which makes accurate measurements of the steady-state ground bond current difficult. Interestingly, the noise characteristics from two identical $3 \mathrm{~kW}$ inverters (same make/model) with two identical $2.4 \mathrm{~kW}$ arrays (two strings of six $200 \mathrm{~W}$ mono-Si modules) can produce different switching noise patterns - although the RMS current and the mean current are within $4 \mathrm{~mA}$ of each other.

Table II: After retrofitting central inverters on commercial roofmounted systems with CSM equipment, a major EPC firm was able to increase the detection of latent ground faults and eliminate fire events across its fleet.

\begin{tabular}{|l|c|c|}
\hline & $\begin{array}{c}\text { Fuse-based } \\
\text { GFPD }(6 \text { years })\end{array}$ & $\begin{array}{c}\text { Post-CSM retrofit } \\
(3 \text { years })\end{array}$ \\
\hline Ground-fault detections & -- & 20 \\
\hline Nuisance Trips & -- & 9 \\
\hline Fires & 9 & 0 \\
\hline
\end{tabular}
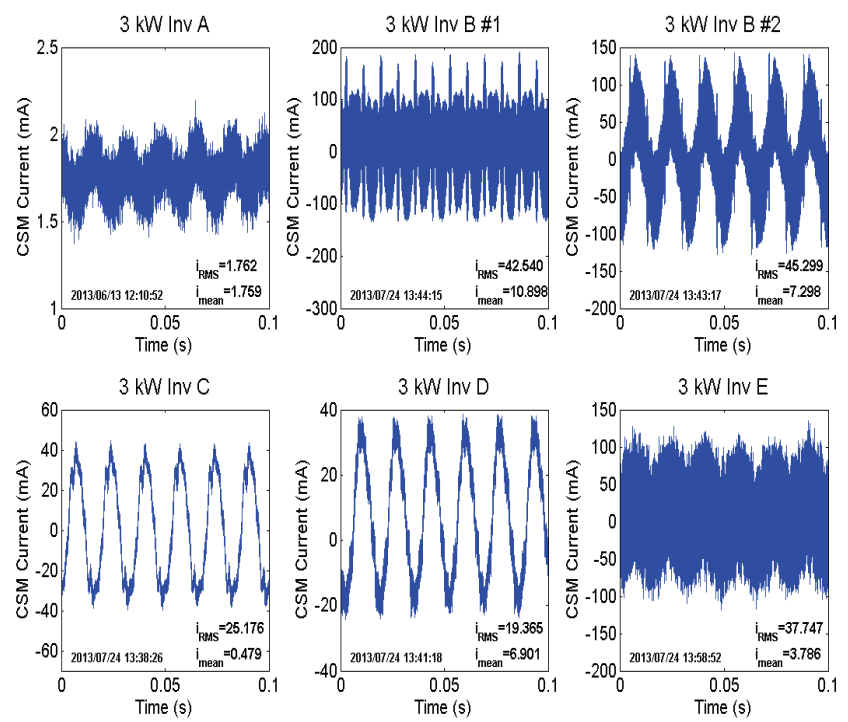

Fig. 16. CSM noise from inverter switching.

\section{Test Case \#2 Discussion}

Although SPICE simulations can successfully predict average leakage and fault current values via CSM, such as those shown in Fig. 15, it cannot describe the complicated current waveforms on the ground bond due to inverter switching schemes, which can lead to nuisance tripping events (such as the nine events identified in Table II).

In conjunction with the EPC, the nuisance trip events in their fleet were analyzed and four separate causes of nuisance tripping were identified: thunderstorm events, noise on the ground bond, ac disturbances, and faulty equipment. The nine nuisance events primarily occurred early in the learning curve with the CSM equipment, while the EPC was still actively using averaging techniques to investigate proper threshold values. 
Fig. 17. Proposed trip time curve for PV arrays based on $750 \mathrm{~J}$ safety limit.

Lightning and spurious measurements were the primary causes of these unwanted trip events. The EPC was eventually able to eliminate these unwanted trips by increasing the CSM trip delay setting from 1 second to 3 seconds, which allows for quick transient currents to pass through the ground bond without tripping the unit. After identifying excessive noise on the ground bond as the cause of unwanted trips at one site, the EPC resolved the problem by using a shielded CT in place of the standard version. We attribute the remaining unwanted trip events to disturbances on the AC grid and one faulty CSM CT.

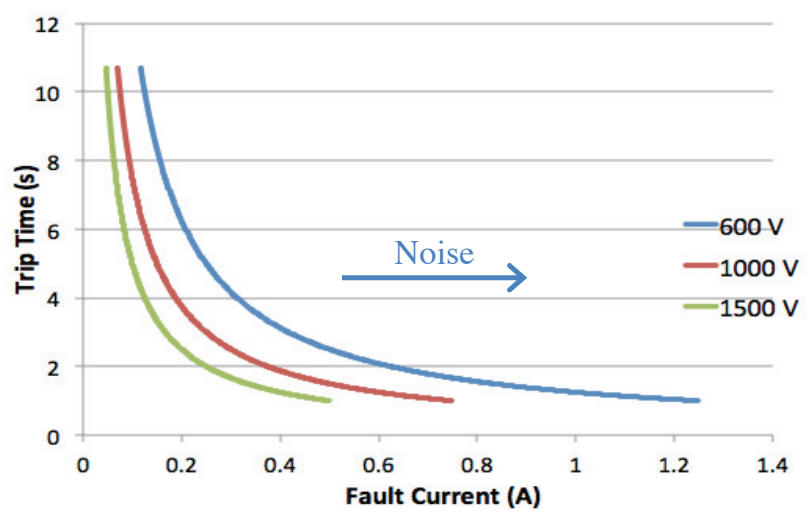

Fig. 18. Trip-time vs. Fault Current curves for arrays with different Voc values that would be used for CSM and RCD GFPDs to ensure fault power is below $70 \mathrm{~W}$ or $750 \mathrm{~J}$.

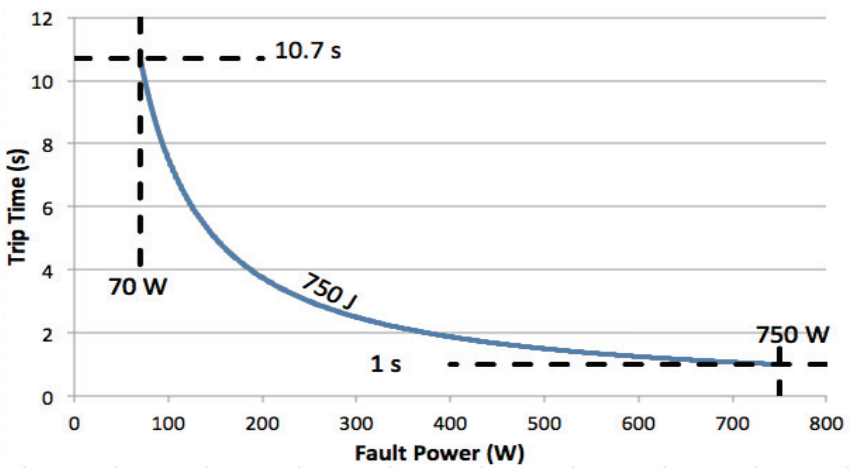

From IEC 60364-4-42 [26], the maximum power that can be dissipated safely through an enduring fault without risk of a fire is $70 \mathrm{~W}$ instantaneous power or an equivalent energy of $750 \mathrm{~J}$. A maximum allowable energy value of $750 \mathrm{~J}$ makes it possible to formulate a trip time vs. fault power curve for any PV system, as shown in Fig. 17. Assuming a worse case, where the array is at $\mathrm{V}_{\mathrm{oc}}$ and supplying all the current through the fault (which is impossible in practice, but does give an added safety factor), then the trip-time curve for a current sensing device (i.e. CSM or RCD) would be described by:

$$
t_{R C D_{-} \text {trip }}(s)=\left\{\begin{array}{ccr}
\text { No trip } & \text { for } & \mathrm{P}_{\text {fault }}<70 \mathrm{~W} \\
\frac{750}{I_{\text {fault }} \cdot V_{o c}} & \text { for } & 70 \mathrm{~W} \leq \mathrm{P}_{\text {fault }}<750 \mathrm{~W} \\
1 & \text { for } & \mathrm{P}_{\text {fault }} \geq 750 \mathrm{~W}
\end{array}\right.
$$

This equation yields a series of curves that are dependent on array $\mathrm{V}_{\mathrm{oc}}$, as in (10). Neglecting noise on the ground bound due to inverter and module leakage, a proper RCD/CSM thresholding should be changed in the standards to correspond to (10). However, the presence of noise will necessitate shifting the curves in Fig. 18 to the right by the maximum amount of leakage expected in normal operating conditions. As has been stated previously, the sub-second noise due to inverter switching can vary greatly from manufacturer-tomanufacturer as well as device-to-device in the same product line.

To accurately set a proper threshold, the subsecond noise characteristics over the entire normal operating regime should be recorded using an oscilloscope and voltage/current probes. The maximum leakage, plus a margin (e.g. 50\%) should be added to (10) to set an optimal threshold. For example, for inverter D in Fig. 16, the trip time curve shown in Fig. 18 should be shifted to the right by $60 \mathrm{~mA}$ (40 mA for noise plus $20 \mathrm{~mA}$ as margin). Due to the variability from unit-to-unit, this should be done to determine the correct trip point for every unit.

\section{ISOLATION MONITORING}

$\mathrm{R}_{\text {iso }}$ measurements are carried out on ungrounded systems (or grounded systems which are temporary disconnected from earth ground) by injection of a voltage pulse into one of the two CCCs (the non-pulsed CCC is left floating) of the PV system by an external power source. Neglecting array capacitance and noise sources, the ground isolation can then be calculated from the current draw on the power source, represented in (11). If the isolation is measured to be below a certain threshold, the isolation monitor trips.

$$
R_{\text {iso }}=\frac{V_{\text {applied }}}{I\left(V_{\text {applied }}\right)-I\left(V_{\text {applied }}=0\right)}
$$

This process is carried out with both positive and negative polarity pulses on one or both CCCs. The pulse polarity and CCC choice does not affect the measurement of the fault as long as there is sufficient illumination to forward bias the module photodiodes. In low illumination conditions, the pulse will travel through the bypass diodes. One pulse polarity will pass through the bypass diodes and measure the fault, as long as the pulse magnitude $\left(\mathrm{V}_{\text {applied }}\right)$ is large enough to overcome the voltage drop of the multiple bypass diodes in the array. The opposite pulse polarity will be blocked by the bypass diodes, possibly leading to anomalous $\mathrm{R}_{\text {iso }}$ readings, if this is 
not considered. The parasitic resistance of the bypass diodes will add slight position dependence in low-light conditions.

Much like CSM and RCD, the range of detectable ground faults for $\mathrm{R}_{\text {iso }}$ measurements depends on the thresholds used to define the presence of a fault. Unlike CSM and RCD, $\mathrm{R}_{\text {iso }}$ measurements are heavily influenced by the capacitance of the PV modules to ground. This means that, especially for larger arrays, the time period of measurement can be long and $\mathrm{R}_{\text {iso }}$ is not an appropriate method to quickly measure and prevent dangerous high-current faults from causing fires. However, when used with an additional detection device (i.e. fuse, CSM, or RCD), which operate on small time-scales, $\mathrm{R}_{\text {iso }}$ is effective at finding the existence of latent faults during a 'morning check' before the inverter begins to export power.

The detectable fault region of $\mathrm{R}_{\text {iso }}$ measurements depends on the threshold used to define the presence of a fault. Ideal detection thresholding maximizes the balance between system safety and uptime, and is essential to the performance and reliability of the PV array and the safety of those around the system.

\section{Numerical Model}

The Sandia ground fault SPICE models were previously used to model $\mathrm{R}_{\text {iso }}$ measurements for utility-scale arrays in both unfaulted [23] and faulted states [27] and present a theoretical understanding of fault current/power and $\mathrm{R}_{\text {iso }}$ trip thresholds for safe operation of PV arrays. As determined in previous work [23], the array $\mathrm{R}_{\text {iso }}$ can be calculated by (12) and is a function of module isolation $\left(R_{\text {module }}\right)$, inverter isolation $\left(R_{\text {inv }}\right)$, fault resistance $\left(R_{\text {fault }}\right)$, number of strings in the array $(\mathrm{S})$ and modules in a string $(\mathrm{M})$, as well as the equipment ground conductor (EGC) resistance $\left(\mathrm{R}_{\mathrm{EGC}}\right)$.

$$
R_{\text {iso }}=\frac{1}{\frac{S \cdot M}{R_{\text {module }}}+\frac{1}{R_{i n v}}+\frac{1}{R_{\text {fault }}}}+R_{E G C}
$$

The leakage or isolation resistance to ground depends on both PV module and inverter technology [28-32] and can drastically affect the detectable region of the $R_{\text {iso }}$ measurements space (Fig. 19). At high values of $R_{\text {fault }}$ $\left(R_{\text {fault }} \geq 100 \mathrm{k} \Omega\right.$, as seen in a healthy systems), the array $R_{\text {iso }}$ is dominated by the isolation of the module and other balanceof-system (BOS) components to ground. The size of the array $(\mathrm{S}, \mathrm{M})$ and the specific isolation of these components $\left(\mathrm{R}_{\text {module }}\right.$, $R_{\text {inv }}$ ) can have a significant effect on fault detectability, since it is not possible to detect the presence of a fault with a larger resistance than the system itself. At low fault resistances, the $\mathrm{R}_{\text {iso }}$ measurement is dominated by the series EGC resistance.

Inverter isolation can be a significant contribution to overall system $\mathrm{R}_{\text {iso }}$, especially in utility-scale arrays. Previous analysis of large PV arrays [23] showed modules can have several hundred $\mathrm{M} \Omega$ to $\mathrm{G} \Omega$ of isolation per module while inverter isolation values can be as low as tens of $\mathrm{k} \Omega$, even when nominally disconnected from ground. These inverter leakage pathways to ground significantly affect baseline $R_{\text {iso }}$ readings and therefore negatively impact the detectability of high-to-moderate impedance faults.

\section{Analytical Model}

In order to determine the maximum allowable trip threshold for an array, it is necessary to solve for the fault current and define an allowable fault current/power below which the array can still be considered to exist in a safe condition. In general, the fault current for an arbitrary location in an array is not analytically solvable. However, the worst-case scenario (fault at a current carrying conductor) has an analytical form since the inverter acts as a current divider circuit with impedance $\mathrm{R}_{\text {inv }}$.

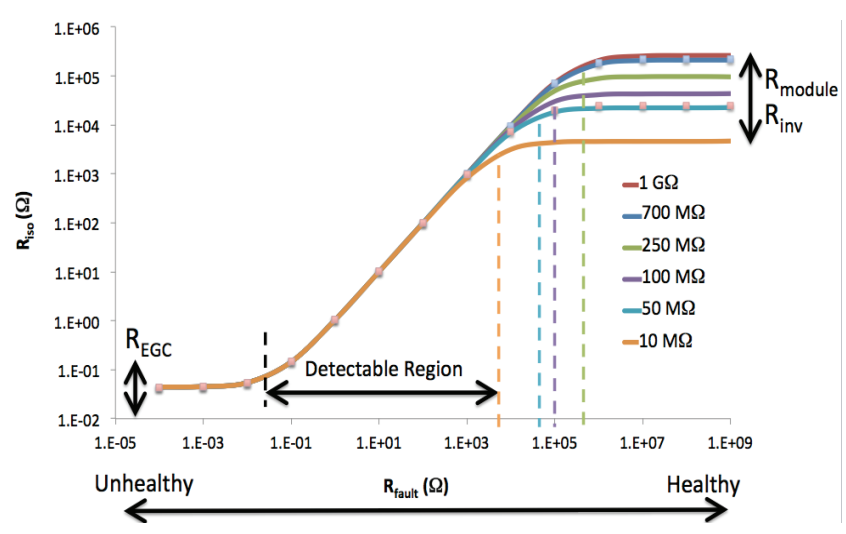

Fig. 19. $\mathrm{R}_{\text {iso }}$ as a function of $\mathrm{R}_{\text {fault }}$ for different healthy system isolations to ground. Changes in inverter or module isolation can have significant impacts on the detectability of faults.

The fault current through a fault during array operation can be described for an ungrounded array by (13).

$$
I_{\text {fault }}=\frac{V_{o c}}{2 \cdot\left(R_{\text {iso }}+R_{\text {fault }}\right)}
$$

For a grounded array, if we assume a ground fault of resistance $\mathrm{R}_{\text {fault }}$ exists at the ungrounded CCC in parallel with an inverter with impedance, $\mathrm{R}_{\text {inv }}$ (Fig. 20), then current (I) from the array will be split between the fault $\left(\mathrm{I}_{\text {fault }}\right)$ and the inverter $\left(\mathrm{I}-\mathrm{I}_{\text {fault }}\right)$.

Using Ohm's Law, the voltage drop across both pathways is equal and can be described by

$$
I_{\text {fault }} \cdot R_{\text {fault }}=\left(I-I_{\text {fault }}\right) \cdot R_{\text {inv }}
$$

Assuming that the MPP does not change with the existence of a fault (an acceptable approximation for utility scale arrays and faults that are greater than $\sim 1 \Omega$ ), then the supplied current from the array (I) is equal to $\mathrm{I}_{\mathrm{mp}}$, the inverter impedance $\left(R_{\text {inv }}\right)$ is equal to $R_{m p}$, and the fault current can be described by 


$$
I_{\text {fault }}=I_{m p}\left[1-\frac{R_{\text {fault }}}{R_{m p}+R_{\text {fault }}}\right]
$$

A worst-case approximation for the current through the fault assumes that $\mathrm{R}_{\text {fault }} \ll \mathrm{R}_{\mathrm{inv}}$. In this case, (15) reduces (16).

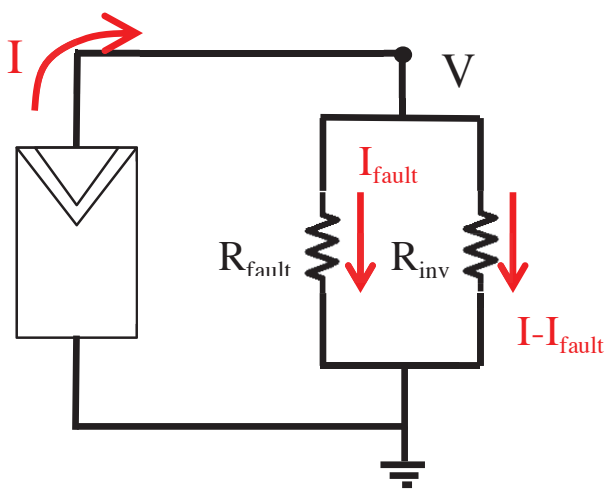

Fig. 20. Schematic of ground fault at ungrounded CCC

$$
I_{\text {fault }}=\frac{V}{R_{\text {fault }}} \approx \frac{V_{o c}}{R_{\text {fault }}}
$$

Although the current at $\mathrm{V}_{\mathrm{oc}}$ is, by definition, equal to zero and these two conditions are mutually exclusive, it gives an added safety margin to assume that the array is in both a high voltage and high current state. (15) and (16) match well with the results obtained from SPICE simulations (Fig. 21).

It is apparent from (13) and (16) that grounded arrays provide significantly more fault current than ungrounded arrays. This is due to a "clamping" effect of ungrounded systems, where the available fault current is limited because the fault re-references the ground of the floating array. That is, when an ungrounded system develops a fault condition, the array becomes referenced to ground at the point of the fault and it, effectively, turns into a grounded system.

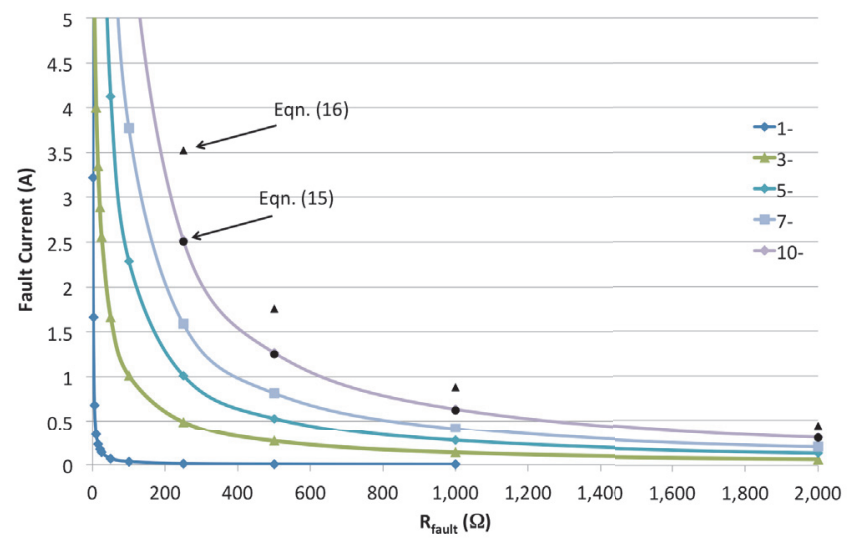

Fig. 21. SPICE simulations (colored lines) of fault current vs fault impedance for ground faults at different locations of a $1000 \mathrm{~V}, 750$ $\mathrm{kW}$ array compared to analytical equations (black points).
Since grounded systems provide much more power to the fault, they are significantly more dangerous than ungrounded systems. As a matter of safety, the threshold for an array should be set for the worst-case fault: a grounded system faulted at the ungrounded CCC.

As described previously, IEC 60364-4-42 dictates that the maximum power that can be dissipated safely through an enduring fault without risk of a fire is $70 \mathrm{~W}$ instantaneous power or an equivalent energy of $750 \mathrm{~J}$. This gives rise to the trip-time curve for a current sensing device (i.e. CSM or RCD) as described by (10).

However, $\mathrm{R}_{\text {iso }}$ is a very slow detection method due to array capacitance and is therefore inappropriate for quick fault mitigation that is more applicable to trip-time curves. $R_{\text {iso }}$ is most effectively used to give binary yes/no signal (most likely at morning check) regarding the safety of the array. Therefore, the trip setting should only be concerned with the highest $\mathrm{R}_{\text {fault }}$ value that could still cause a fire condition (i.e. the value of $R_{\text {fault }}$ that corresponds to a fault power of $70 \mathrm{~W}$ ).

Instead of requiring a trip time as a function of fault current as in CSM or RCD solutions, $\mathrm{R}_{\text {iso }}$, has a trip point based on the isolation of the array according to (12). This trip point should be set to detect any fault with a fault power of $70 \mathrm{~W}$ or greater. The maximum allowable fault impedance can be calculated from the maximum allowable fault power and array $\mathrm{V}_{\mathrm{oc}}$, as in (16). This critical fault impedance value could then be transformed into a $R_{\text {iso }}$ trip setting using (12).

For example, in a $1000 \mathrm{~V}$ grounded system, a $70 \mathrm{~W}$ fault would be the result of a fault current of $70 \mathrm{~mA}$. This critical fault current would be caused by an $\mathrm{R}_{\text {fault }}$ value of $14.3 \mathrm{k} \Omega$, as calculated by (16). A system designer, with knowledge of the specific array configuration $(S, M)$, module leakage $\left(R_{\text {module }}\right)$, and inverter isolation $\left(\mathrm{R}_{\text {inv }}\right)$ could then use (12) to find the proper $\mathrm{R}_{\mathrm{iso}}$ threshold for the array in question $\left(\mathrm{R}_{\mathrm{EGC}}\right.$ is assumed to be zero for thresholding purposes).

Unfortunately, for standards development organizations (SDOs) and inverter manufacturers without detailed knowledge of specific array configuration, it is not practical to describe necessary trip thresholds based on array configuration $(\mathrm{S}, \mathrm{M})$. It is possible to remove the array configuration aspects from (12) and completely describe $\mathrm{R}_{\text {iso }}$ with array electrical information and allowable fault power.

In this case, the number of modules in an array (S.M) is a function of the power of the array $\left(\mathrm{P}_{\text {inv }}\right)$, power of a module $\left(\mathrm{P}_{\mathrm{mod}}\right)$, and DC-to- $\mathrm{AC}$ ratio $\left(\mathrm{P}_{\mathrm{DC}} / \mathrm{P}_{\mathrm{AC}}\right)$ as seen in (17).

$$
S \cdot M=\frac{P_{i n v}}{P_{\text {mod }}} \cdot\left(\frac{P_{D C}}{P_{A C}}\right)
$$

There exists an implicit assumption in $\mathrm{R}_{\text {module }}$ on the number of modules (more specifically, in the area of modules present, as module isolation is limited by IEC 61215 [33] to no less than $\left.40 \mathrm{M} \Omega \cdot \mathrm{m}^{2}\right)$. The module area (A) is a function of module power $\left(\mathrm{P}_{\mathrm{mod}}\right)$ and module efficiency $(\eta)$ as shown in (18). 


$$
A=\frac{P_{\bmod }}{1000 \frac{W}{m^{2}}}
$$

By inserting (17) and (18) into (12), the value of $R_{\text {iso }}$ can be described only in terms of the electrical state of an array,

$$
R_{\text {iso }}=\frac{1}{\frac{P_{i n v} \cdot\left(\frac{P_{D C}}{P_{A C}}\right)}{R_{\text {module }} \cdot 1000 \cdot \eta}+\frac{1}{R_{i n v}}+\frac{P_{\text {fault }}}{V_{o c}^{2}}}
$$

This equation can be used to determine a $\mathrm{R}_{\text {iso }}$ threshold for a given array.

\section{Results and Discussion}

Based on the analytical and numerical analysis presented here, let us assume that the SDO wants to set a $R_{\text {iso }}$ threshold to limit fault power $\left(\mathrm{P}_{\text {fault }}\right)$ to $70 \mathrm{~W}$. A conservative estimation of $R_{\text {iso }}$ threshold would be to assume a worst-case situation for the array in which large area, leaky modules $\left(40 \mathrm{M} \Omega \cdot \mathrm{m}^{2}, 10 \%\right.$ efficient) with a low inverter impedance to ground $(20 \mathrm{k} \Omega)$ are installed on a $500 \mathrm{~kW}, 1000 \mathrm{~V}$ system. In this case (shown as the blue curve in Fig. 22) the unfaulted array would have a $R_{\text {iso }}$ value of $7.85 \mathrm{k} \Omega$ with a trip threshold calculated to be $4.08 \mathrm{k} \Omega$ using (19).

If, however, a system designer installs significantly better modules and low leakage inverter $\left(1.08 \mathrm{G} \Omega \cdot \mathrm{m}^{2}, 20 \%\right.$ efficient, $\mathrm{R}_{\text {inv }}=500 \mathrm{k} \Omega$, red curve in Fig. 22), the unfaulted $\mathrm{R}_{\text {iso }}$ would increase to $230.6 \mathrm{k} \Omega$. This increase would increase the detectability for faults; however, the trip setting calculated for the less efficient modules $(4.08 \mathrm{k} \Omega$, thin dashed line) would yield a maximum allowable fault power of $193 \mathrm{~W}$, resulting in a hazardous condition where a fault dissipating over $70 \mathrm{~W}$ could exist in the system without detection. Therefore, assuming very poor quality modules as a worst-case condition actually decreases system safety.

Conversely, if it is assumed that high-isolation modules are installed $\left(\mathrm{R}_{\text {module }} \rightarrow \infty\right)$ then the array isolation is only a function of fault impedance (purple line in Fig. 22). In this case, the threshold would be set at $14 \mathrm{k} \Omega$. If a system designer installs more leaky modules (blue line in Fig. 22), then there will be nuisance tripping issues as even the $\mathrm{R}_{\text {iso }}$ of the healthy array case $(7.85 \mathrm{k} \Omega)$ is below the determined trip threshold.

Therefore, without knowledge of the array configuration or module quality, it is impossible to determine a trip threshold that provides safety and prevents unwanted tripping issues. Appropriate $\mathrm{R}_{\text {iso }}$ trip thresholds must be determined on an array-by-array basis with sufficient leeway by system operators to adjust trip threshold settings for their particular usage cases.

Although specific, one-size-fits-all $\mathrm{R}_{\text {iso }}$ trip settings are not possible, standards making bodies can define $\mathrm{R}_{\text {iso }}$ trip points in a way that is analogous to the advanced inverter functionality tests in UL 1741 Supplement A [34]. Namely, standards could define a range of required settings, which would be tested at the minimum, average (or default), and maximum set points. The $\mathrm{R}_{\text {iso }}$ could then be adjusted within this range by a qualified operator to optimize the safety for each individual array. NRTL certification would only validate the accuracy of these three points, but qualified technicians would be able to set the trip point anywhere within this range during commissioning.

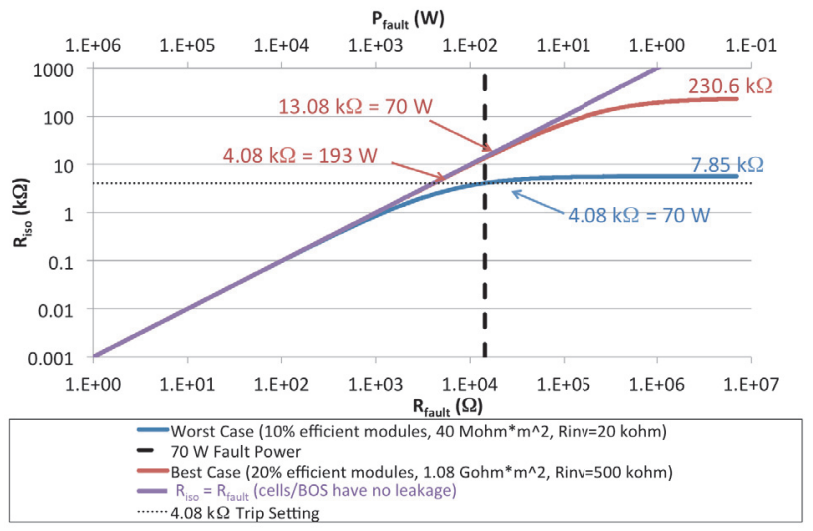

Fig. 22. $\mathrm{R}_{\text {iso }}$ Vs. $\mathrm{R}_{\text {fault }}$ for different module technologies based on (19) ranging from very leaky modules (blue line) to slightly better modules (red line) to non-leaky modules (purple line) with Pinv $=500 \mathrm{~kW}, \mathrm{DC} / \mathrm{AC}=1, \mathrm{VOC}=1000 \mathrm{~V}$. In general, with regard to a priori calculation of $\mathrm{R}_{\text {iso }}$ trip settings, changes in module efficiencies and isolations result in either safety or unwanted tripping issues.

The maximum, minimum, and default set points should be based on the $\mathrm{R}_{\text {iso }}$ equations presented here to ensure no more than $70 \mathrm{~W}$ ground fault power dissipation. Note that an ungrounded system can have higher set points than a grounded system since a first fault will induce much smaller fault currents. However, in the interest of defining a single value, we use grounded systems as a worst case. We propose the minimum allowable $\mathrm{R}_{\text {iso }}$ certification test point would be calculated using (19) and based on a system constructed of modules and an inverter with high leakage currents and low efficiency: $40 \mathrm{M} \Omega \cdot \mathrm{m}^{2}$ module isolation, $10 \%$ efficiency modules, $20 \mathrm{k} \Omega$ inverter isolation.

Since having a low set point is a safety hazard, while having a high set point is only an unwanted tripping risk, the default $R_{\text {iso }}$ would be the highest $R_{\text {iso }}$ set point that would realistically be used in the field. Therefore, the default set point using (19) should be selected using state-of-the-art PV system characteristics $\left(1 \mathrm{G} \Omega \cdot \mathrm{m}^{2}\right.$ isolation, $20 \%$ efficient, $500 \mathrm{k} \Omega$ inverter isolation). A system installer could then adjust the $\mathrm{R}_{\text {iso }}$ to a lower value to correct unwanted tripping issues while still maintaining the array in a safe state.

For testing/certification of $\mathrm{R}_{\text {iso }}$ set point accuracy, it is necessary to define a maximum allowable set point as well. This defines a complete envelope for allowable $R_{\text {iso }}$ trip settings. In this case, we propose the maximum allow set point 
to be a $50 \%$ increase in the difference between the minimum and default set points,

$$
R_{\max }^{i s o}=R_{\text {default }}^{\text {iso }}+1.5 \times\left(R_{\text {default }}^{\text {iso }}-R_{\min }^{\text {iso }}\right)
$$

Fig. 23 shows how the minimum (lower solid blue line), default (dashed line), and maximum (upper solid blue line) $R_{\text {iso }}$ set points determine the available $R_{\text {iso }}$ trip-point envelope (shaded region) and compare to current PV standards [9, 3537]. The minimum $R_{\text {iso }}$ set point presented here matches well with IEC 62548 for utility-scale systems and is more liberal for smaller residential scale systems [36]. The equations presented here are also more liberal than the set points in UL 1741 CRD-2012 for isolated, ungrounded systems [35], although much more conservative than the set points in UL 1741 CRD-2010 for non-isolated (transformerless), ungrounded systems [9]. Similar requirements can be derived for $600 \mathrm{~V}$ and $1000 \mathrm{~V}$ systems using (19). In order to convert these equations to an easy-to-use lookup table for manufacturers, certification engineers, and installers, the $\mathrm{R}_{\text {iso }}$ values for different system sizes were calculated. The system sizes used in the calculations are the average of system size range for each category. An example of using these equations to develop minimum, default, and maximum trip points as a function of system size (system size should be calculated to be inverter rating multiplied by the maximum allowable DC-to-AC ratio) for a $1,500 \mathrm{~V}$ system is shown in Table III.

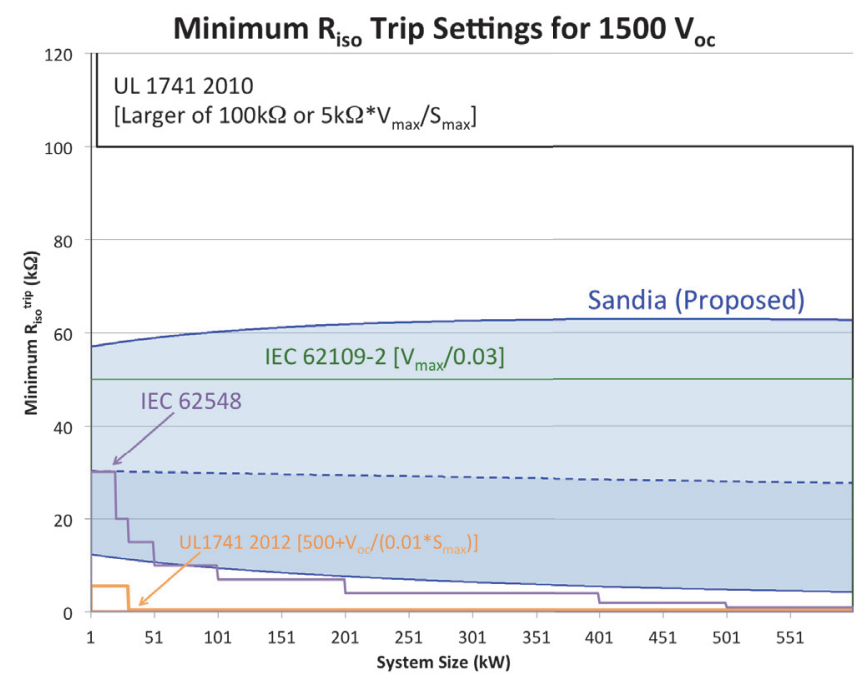

Fig. 23. Allowable adjustable $\mathrm{R}_{\text {iso }}$ range (blue shading) as a function of system size for $1,500 \mathrm{~V}$ systems. The trip points based on the equations presented in this work (blue) are compared to other PV industry standards for $\mathrm{R}_{\text {iso }}$.
Table III: $\mathrm{R}_{\text {iso }}$ recommendations for minimum, maximum, and default set points as a function of system size for a 1,500 V system.

\begin{tabular}{|l|l|l|l|}
\hline System Size $(\mathrm{k} \Omega)$ & $\begin{array}{c}\mathrm{R}^{\text {iso }}{ }_{\text {min }} \\
(\mathrm{k} \Omega)\end{array}$ & $\begin{array}{c}\mathrm{R}^{\text {iso }}{ }_{\text {default }} \\
(\mathrm{k} \Omega)\end{array}$ & $\begin{array}{c}\mathrm{R}^{\text {iso }}{ }_{\text {max }} \\
(\mathrm{k} \Omega)\end{array}$ \\
\hline$\leq 20$ & 12.0 & 30.2 & 57.5 \\
\hline$>20$ and $\leq 30$ & 11.4 & 30.1 & 58.15 \\
\hline$>30$ and $\leq 50$ & 11.0 & 30.1 & 58.75 \\
\hline$>50$ and $\leq 100$ & 10.0 & 29.9 & 59.75 \\
\hline$>100$ and $\leq 200$ & 8.4 & 29.6 & 61.4 \\
\hline$>200$ and $\leq 400$ & 6.4 & 29 & 62.9 \\
\hline$>400$ and $\leq 500$ & 5.2 & 28.5 & 63.45 \\
\hline$\geq 500$ & 4.9 & 28.4 & 63.65 \\
\hline
\end{tabular}

\section{SUMMARY AND CONCLUSIONS}

We have examined ground faults in PV arrays and the efficacy of fuse, RCD/CSM, and $\mathrm{R}_{\text {iso }}$ GFPDs using simulations based on a SPICE ground fault circuit model, experimental ground faults installed on real arrays, and analytical equations. The SPICE model and analytical results were used to determine trends for various ground fault conditions and to ascertain potential benefits of reducing the fuse ratings in PV systems. Decreasing the GFPD fuse ratings to 1 A for systems up to $250 \mathrm{~kW}$ and to 2 A for systems $>250$ $\mathrm{kW}$ would protect against a wider range of ground faults. Further decreasing the fuse ratings below 1 A does not improve the number of faults that can be detected due to larger internal GFPD resistances and a subsequent decrease in fault current. It is necessary to carefully consider the GFPD rating and resistance to optimize the types of ground faults that can be detected.

To demonstrate the efficacy of CSM/RCD fault detection techniques, Sandia partnered with a major EPC firm to reduce the fire risk in PV systems through implementation of RCD ground fault detection equipment. Over three years, the EPC firm has refined the detection thresholds for their systems to minimize unwanted tripping events while maintaining a perfect safety record. Additionally, analysis of one-minute RCD leakage values of 340 co-located inverters found a 5 A trip point to be overly conservative. For these inverters, RCD trip point could be lowered from 5 A to as low as 2.5 A with six 9's confidence that any unfaulted RCD current measurement would be lower than the ground fault setpoint. Statistically, this would correspond to 0.5 trips/year/inverter if single, raw RCD measurement points were considered. In practice, this number would be drastically reduced through the proper use of data windowing, averaging, or other data analysis techniques.

To accurately set a proper threshold for CSM/RCD detectors, the $70 \mathrm{~W}$ maximum allowable fault current determined by IEC 60364-4-42 should be used along with the array $\mathrm{V}_{\mathrm{oc}}$ to derive a trip-time vs. fault current curve. This curve should be shifted to higher current trip settings by the maximum measured subsecond switching noise characteristics 
of the inverter over the normal operating regime plus a margin (e.g. 50\%).

Finally, theoretical equations related to $\mathrm{R}_{\text {iso }}$ were derived for grounded and ungrounded arrays, which can be used to determine appropriate trip thresholds based on allowed fault power. Equations were also developed to allow the calculation of trip threshold without knowledge of the specific array topology. However, in this case, selection of the default

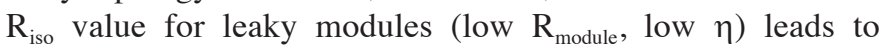
potential safety issues if well-isolated modules are installed; while using well-isolated modules to select the default $\mathrm{R}_{\text {iso }}$ trip threshold leads to possible unwanted tripping issues in systems with leaky modules. Said another way, a default $\mathrm{R}_{\text {iso }}$ value cannot be predetermined for PV inverters because leaky systems will have unwanted tripping and highly isolated systems will not trip before a fire hazard.

Therefore, an a priori calculation of trip threshold cannot mitigate both fire risk and unwanted tripping issues for all possible arrays. Some system knowledge is necessary for the determination of trip points. In general, there is no one-sizefits-all solution and standards bodies may have to determine a range of values that can be set by array operators based on specific details of the array. Therefore, inverter manufacturers and standards development organizations should allow for a range of $\mathrm{R}_{\text {iso }}$ thresholds that can be determined on a case-bycase basis, most likely as part of array commissioning.

Table IV: Summary of ground fault thresholds in U.S. and International Standards and new recommendations from this research.

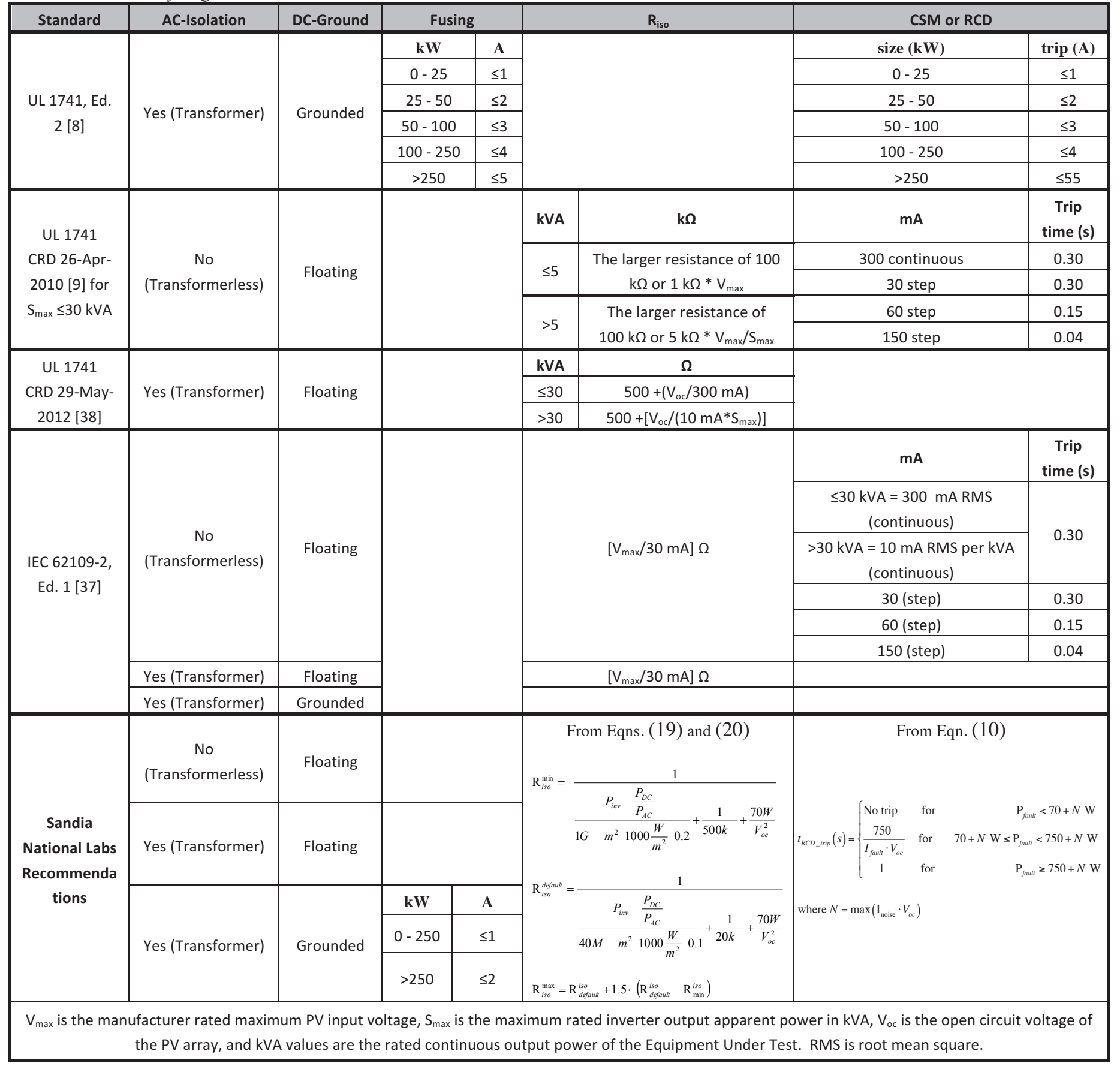


Currently, there are major efforts underway to refine the industry-wide requirements for PV system ground fault protection in U.S. safety standards. The Underwriters Laboratories Standards Technical Panel (STP) for UL 1741 and UL 62109-2 are presently reviewing trip limit proposals for $\mathrm{CSM} / \mathrm{RCD}$ and isolation monitors. The simulations, experiments, and theoretical equations presented here and summarized in Table IV with similar fault protection standards are being used by the STP to justify considerably lower trip limits for PV system ground fault protection than had been required in the past. These lower trip limits will lead to safer arrays with limited unwanted tripping issues. The updated requirements are being incorporated into UL 62109-2, which will likely be available in 2016 .

The specific recommendations to the industry presented in this work have been corroborated by numerical and analytical models as well as experimental data. These include:

1. Decreasing GFPD fuse size is not an appropriate solution to the ground fault blind spot and to fully protect a PV system, fusing must be paired with other GFPDs.

2. For RCD/CSM, the maximum subsecond leakage, plus a margin (e.g. 50\%) should be added to (10) to set an optimal threshold. Present-day thresholds are too liberal according to the data presented here.

3. $\mathrm{R}_{\text {iso }}$ trip thresholds should be based on the maximum fault power equations developed herein for grounded and ungrounded arrays, which can be used without knowledge of the specific array parameters.

\section{ACKNOWLEDGEMENT}

This material is based upon work supported by the U.S. Department of Energy under Award Number DE-FC3607G017034. This work was funded by the DOE Office of Energy Efficiency and Renewable Energy. Sandia National Laboratories is a multi-program laboratory managed and operated by Sandia Corporation, a wholly owned subsidiary of Lockheed Martin Corporation, for the U.S. Department of Energy's National Nuclear Security Administration under contract DE-AC04-94AL85000.

The authors would like to sincerely acknowledge the help of Mark Albers, Greg Ball, and Ken Armijo with data collection and analysis during this work.

\section{REFERENCES}

[1] R. Wills, J. Milke, S. Royle, and K. Steranka, "Commercial Roof-Mounted Photovoltaic System Installation Best Practices Review and All Hazard Assessment " Fire Protection Research Foundation, Final Report. February 2014.

[2] J. C. Wiles, "Photovoltaic System Grounding," Solar America Board for Codes and Standards, Technical Report. Oct 242012.
[3] National Fire Protection Association, "National Electrical Code, 2014 Edition, NFPA70," ed. Quincy, MA.

[4] B. Brooks. (February/March 2011) "Bakersfield Report ". SolarPro Magazine. 62-70.

[5] G. Ball, B. Brooks, J. Johnson, J. Flicker, A. Rosenthal, J. Wiles, et al., "Inverter Ground-fault Detection 'Blind Spot' and Mitigation Methods," Solar American Board for Codes and Standards Technical Report. June 2013.

[6] B. Brooks, "Report of the Results of the Investigation of Failure of the 1.1135 MW Photovoltaic (PV) Plant at the National Gypsum Facility in Mount Holly, North Carolina," Brooks Engineering Draft Report26 May 2011.

[7] J. Flicker and J. Johnson, "Analysis of Fuses for 'Blind Spot' Ground Fault Detection in Photovoltaic Systems," Solar American Board for Codes and Standards, Technical Report. June 2013.

[8] Underwriters Laboratories 1741 Ed. 2, "Inverters, Converters, Controllers and Interconnection System Equipment for Use With Distributed Energy Resources," ed, 2010.

[9] Underwriters Laboratories 1741, "Certification Requirement Decision, Non-Isolated EPS Interactive PV Inverters Rated Less Than 30kVA," ed, 26-April2010.

[10] Y. Zhao, B. Lehman, J. de Palma, J. Mosesian, and R. Lyons, "Challenges to overcurrent protection devices under line-line faults in solar photovoltaic arrays," Transactions of the IRE Professional Group on Audio, pp. 20-27, Sep 012011.

[11] L. W. Nagel and D. O. Pederson, "SPICE (Simulation Program with Integrated Circuit Emphasis).", ed: University of California, Berkeley, 1973, p. 62.

[12] J. Flicker and J. Johnson, "Photovoltaic Ground Fault and Blind Spot Electrical Simulations," Sandia National Laboratories2013.

[13] Y. Zhao, B. Lehman, J. de Palma, J. Mosesian, and R. Lyons, "Challenges to overcurrent protection devices under line-line faults in solar photovoltaic arrays," Audio, Transactions of the IRE Professional Group on, pp. 20-27, Sep 012011.

[14] L. W. Nagel and D. O. Pederson, "SPICE (Simulation Program with Integrated Circuit Emphasis)." vol. ERL-M382, ed: University of California, Berkeley, 1973, p. 62.

[15] L. Castaner and S. Silvestre, Modelling Photovoltaic Systems using PSPICE. Chichester, West Sussex, England: John Wiley and Sons Ltd, 2002.

[16] A. Devasia and S. K. Kurinec, "Teaching solar cell I$\mathrm{V}$ characteristics using SPICE," American Journal of Physics, vol. 79, p. 1232, 2011. 
[17] J. Worden and M. Zuercher-Martinson. (2009, May) How Inverters Work. SolarPro. 68-85. Available: http://xiazai.inktronics.com.cn/Uploadfile/DownFile/ 10-08-13/100813131907_hjkg.pdf

[18] J. Flicker, R. Kaplar, M. Marinella, and J. Granata, "PV Inverter Performance and Reliability: What is the Role of the Bus Capacitor?," in Photovoltaic Specialists Conference (PVSC), Austin, TX, 2012, p. 6.

[19] J. Flicker and J. Johnson, "Photovoltaic ground fault and blind spot electrical simulations," Sandia National Laboratories, 2013.

[20] M. Alam, F. H. Khan, J. Johnson, and J. Flicker, "A Comprehensive Review of Catastrophic Faults in PV Arrays: Types, Detection and Mitigation Techniques," IEEE Journal of Photovoltaics, in review 20142014.

[21] J. Flicker and J. Johnson, "Electrical simulations of series and parallel PV arc-faults," presented at the IEEE 39th Photovoltaic Specialists Conference (PVSC), 2013, Tampa, FL, 2013.

[22] Littelfuse, "POWR-GARD Fuse Datasheet," November 2011.

[23] J. Flicker, J. Johnson, M. Albers, and G. Ball, "Recommendations for CSM and Riso ground fault detector trip thresholds," in Photovoltaic Specialist Conference (PVSC), 2014 IEEE 40th, 2014, pp. 3391-3397.

[24] J. Flicker, K. Armijo, and J. Johnson, "Recommendations for RCD Ground Fault Detector Trip Thresholds," in 29th European Photovoltaic Solar Energy Conference and Exhibition (EUPVSEC), Amsterdam, Netherlands, 2014, pp. 2740 - 2746.

[25] J. Flicker, J. Johnson, and M. Albers. (2015, November/December 2015) "Resolving Fire Hazards from the Ground-Fault Detection Blind Spot". SolarPro Magazine. Available: http://solarprofessional.com/articles/designinstallation/resolving-fire-hazards-from-the-groundfault-detection-blind-spot

[26] International Electrotechnical Commission (IEC) Standard 60364-4, "Low-voltage electrical installations," in Part 42: Protection for safety Protection against thermal effects, ed. Geneva, 2010.

[27] J. Flicker, J. Johnson, M. Albers, and G. Ball, "Recommendations for Isolation Monitor Ground Fault Detectors on Residential and Utility-Scale PV Systems," in Photovoltaic Specialist Conference (PVSC), 2015 IEEE 42nd, New Orleans, LA, 2015.

[28] SMA, "Insulation Resistance (Riso) of NonGalvanically Isolated PV Plants, SMA Technical Information Note, Version 2.2," URL: http://files.sma.de/dl/7418/Riso-UEN123622.pdf, accessed 10 Feb 2014.
[29] J. C. Hernandez, P. G. Vidal, and A. Medina, "Characterization of the Insulation and Leakage Currents of PV Generators: Relevance for Human Safety," Renewable Energy, vol. 35, pp. 593-601, March 2010.

[30] Xiaomeng Su, Yaojie Sun, and Yandan Lin, "Analysis on Leakage Current in Transformerless Single-Phase PV Inverters Connected to the Grid," presented at the Power and Energy Engineering Conference (APPEEC), 2011 Asia-Pacific 28 March 2011.

[31] O. Lopez, R. Teodorescu, F. Freijedo, and J. DolvalGandoy, "Leakage Current Evaluation of a Single Phase Transformerless PV Inverter Connected to the Grid," in Twenty Second Annual IEEE Applied Power Electronics Conference, APEC 2007, Anaheim, CA, Feb 25-Mar 1 2007, pp. 907 - 912.

[32] Lin Ma, Fen Tang, Fei Zhou, Xinmin Jin, and Yibin Tong, "Leakage Current Analysis of a Single-Phase Transformer-less PV Inverter Connected to the Grid," in IEEE International Conference on Sustainable Energy Technologies, 2008 (ICSET 2008.), Singapore, 24-27 Nov 2008, pp. 285 - 289

[33] IEC Standard 61215, "Crystalline silicon terrestrial photovoltaic (PV) modules. Design qualification and type approval," ed. 2.0: Geneva, 2005.

[34] Underwriters Laboratories, "1741 Supplement A," in Grid Support Utility Interactive Inverters And Converters, ed, 2016 (unpublished).

[35] U. Laboratories, "1741 Certification Requirement Decision," in Isolated Inverters Intended for Use with Ungrounded PV Arrays, ed, 29-May-2012.

[36] International Electrotechnical Commission 62548 Ed. 1.0, "Photovoltaic (PV) arrays - Design requirements," International Electrotechnical Commission, Geneva, Jul 2013.

[37] International Electrotechnical Commission IEC62109-2 ed 1.0, "Safety of Power Converters for Use in Photovoltaic Power Systems - Part 2: Particular Requirements for Inverters," ed. Geneva, Switzerland, 2011.

[38] Underwriters Laboratories 1741, "Certification Requirement Decision, Isolated Inverters Intended for Use with Ungrounded PV Arrays," 29-May-2012. 